\title{
A PRACTICE-ORIENTED METHOD FOR ESTIMATING ELASTIC FLOOR RESPONSE SPECTRA
}

\author{
Kieran Haymes ${ }^{1}$, Timothy J. Sullivan ${ }^{2}$ and Reagan \\ Chandramohan ${ }^{3}$
}

(Submitted November 2019; Reviewed December 2019; Accepted March 2020)

\begin{abstract}
A practice-oriented modal superposition method for setting elastic floor acceleration response spectra is proposed in this paper. The approach builds on previous contributions in the literature, making specific recommendations to explicitly consider floor displacement response spectra and accounts for uncertainty in modal characteristics. The method aims to provide reliable predictions which improve on existing code methods but maintain simplicity to enable adoption in practical design. This work is motivated by recent seismic events which have illustrated the significant costs that can be incurred following damage to secondary and nonstructural components within buildings, even where the structural system has performed well. This has prompted increased attention to the seismic performance of nonstructural components with questions being raised about the accuracy of design floor acceleration response spectra used in practice. By comparing floor acceleration response spectra predicted by the proposed method with those recorded from instrumented buildings in New Zealand, it is shown that the proposed approach performs well, particularly if a good estimate of the building's fundamental period of vibration is available.
\end{abstract}

\section{INTRODUCTION}

The objective of this work is to develop a practice-oriented prediction method that is suitable for the definition of both floor acceleration response spectra and floor displacement response spectra. The scope of this work is currently limited to structural systems that respond elastically. The proposed method is based on the concept of modal superposition. Modifications are made to the amplification factor shape proposed by Kehoe and Hachem [1] as adopted in ASCE 7-16 [2], with further work building on the proposals by Calvi and Sullivan [3], and Welch and Sullivan [4]. The method developed was verified against data recorded by instrumented buildings in New Zealand from the GeoNet Structural Array [5].

This work is motivated by the recognition by the earthquake engineering industry that despite decades of improvement in the seismic design of buildings, the damage and disruption caused by earthquakes remains high $[6 ; 7]$. The losses associated with damage to nonstructural components are recognised to be particularly high, causing disruption and posing a safety hazard to occupants [8]. Significant losses incurred by nonstructural components have at times attracted scrutiny over the future of otherwise repairable structures [6].

In a broader context, poor seismic performance of nonstructural components does not fall solely with the inability to predict design accelerations. Instead, the poor performance may be due to a lack of bracing, failure to follow standards, or lack of consideration. Baird and Ferner [9] found that many components that failed in the Kaikōura earthquake were not braced at all, and those that were performed well. Ferner et al. [10] found that in New Zealand the responsibility for the seismic design and construction of bracing for nonstructural components is typically not within the scope of project engineers, instead falling to those with limited familiarity with seismic requirements such as contractors, architects, and service engineers. Poor consideration may be due in part to building consent authorities often not requiring specific seismic design or construction review producer statements. Applied Technology Council [11] found similar issues in the USA. This paper acknowledges that a holistic approach to the seismic performance of nonstructural components is required. Further, an aim of this research is to produce a method for predicting design accelerations which is able to be used by those with limited knowledge on the structural properties of the structure.

Reliable seismic design of nonstructural components is impeded by the difficulty in accurately predicting the acceleration and displacement demands imposed on them. These demands can be estimated using either empirical floor acceleration response spectrum prediction equations or advanced dynamic analyses. Current methods for defining floor acceleration response spectra in design standards, however, have been seen to be inaccurate [7; 12; 13], posing the need for improved code provisions.

Recently proposed floor acceleration response spectrum prediction methods have generally focussed on modal response spectral analyses. Several studies have developed procedures (e.g., $[1 ; 3 ; 4 ; 14])$ which were verified against numerical simulations. The focus of previous work has been predominantly on floor acceleration response spectra, with the notable exception of the work by Calvi [15] on floor displacement response spectra. This paper is differentiated through its consideration of both floor acceleration response spectra and floor displacement response spectra, its verification against instrumented structure data, and through its aim to enable simple use by practicing engineers.

\footnotetext{
${ }^{1}$ Corresponding Author, Student, University of Canterbury, Christchurch, kieran.haymes@pg.canterbury.ac.nz (Member)

2 Professor, University of Canterbury, Christchurch, timothy.sullivan@canterbury.ac.nz (Member)

${ }^{3}$ Lecturer, University of Canterbury, Christchurch, reagan.c@canterbury.ac.nz (Member)
} 


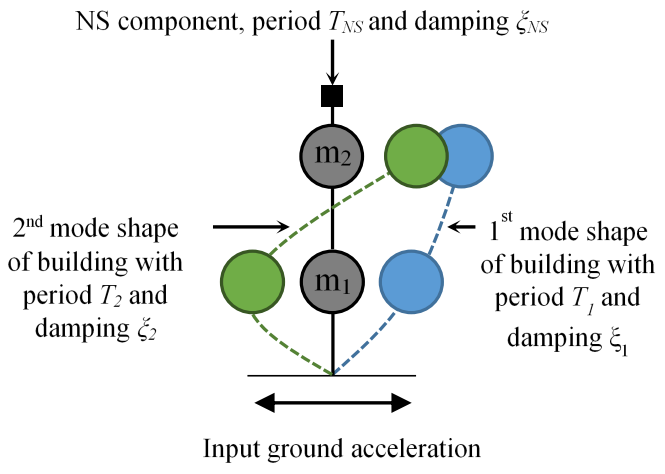

(a) Mode shapes of the building.

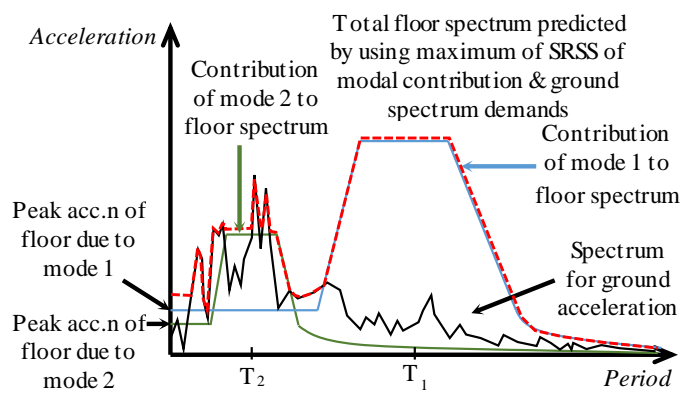

(b) Proposed floor spectrum.

Figure 1: Overview of the proposed method.

\section{PROPOSED FLOOR ACCELERATION RESPONSE SPECTRUM PREDICTION METHOD}

The floor acceleration response spectrum represents the peak acceleration demand imposed on a nonstructural element located at a floor as a function of its fundamental period of vibration, $T_{N S}$. Figure 1 provides an overview of the method for constructing floor acceleration response spectra proposed in this work. The new approach can be seen as an extension to the work proposed by Calvi and Sullivan [3], and Welch and Sullivan [4]. The approach uses the mode shapes and periods of the building (Figure 1(a)) to first compute the peak floor acceleration demands for each mode. Subsequently, dynamic amplification factors that depend on the damping ratio of the nonstructural component and the ratio of the nonstructural element fundamental period to each building period are used to establish the contributions of different modes to the total floor acceleration response spectrum (Figure 1(b)). Finally, the predicted floor acceleration response spectrum is taken as the maximum spectral acceleration considering the acceleration response spectrum at the ground and the square-root-sum-of-squares (SRSS) of all of the modal contributions at each nonstructural period, $T_{N S}$. To assist in more easily estimating the parameters required, a number of assumptions and simplifications can be made, as further discussed below.

\section{Modal Contribution Equation}

In the prediction method, the contribution of mode $i$, at floor $j$, to the floor acceleration response spectrum at the period of vibration of the nonstructural component, $T_{N S}$, is computed using Equation 1:

$$
S_{F A, i, j}\left(T_{N S}, \xi_{N S}\right)=\left|\Gamma_{i} \phi_{i, j}\right| S_{G A}\left(T_{i}, \xi_{s t r}\right) D A F\left(r_{T, i}\right)
$$

where $\Gamma_{i}$ is the participation factor of mode $i$;

$\phi_{i, j}$ is the modal shape coordinate of mode $i$, at floor $j$;

$S_{G A}\left(T_{i}, \xi_{s t r}\right)$ is the ground acceleration response spectral ordinate corresponding to the period of vibration of mode $i$, scaled to the damping of the structure, $\xi_{s t r}$, of $5 \%$; and

$D A F\left(r_{T, i}\right)$ is the Dynamic Amplification Factor used to describe the resonant behaviour between the fundamental mode of vibration of the nonstructural element, $T_{N S}$, and mode of vibration $i$ of the building, $T_{i}$.

Equation 1 follows the form of previous methods, where the peak floor acceleration, $\Gamma_{i} \phi_{i, j} S_{G A}\left(T_{i}, \xi_{s t r}\right)$, is multiplied by a factor accounting for resonance between the nonstructural component and the building, the dynamic amplification factor $D A F[1 ; 2 ; 4$; 7; 14].

The appendix of this paper provides values for approximate participation factors and modal coordinates that could be used in lieu of results from accurate eigenvalue analysis.

\section{Dynamic Amplification Factor}

The phenomenon that most governs the shape of the floor acceleration response spectrum is resonance between the modes of vibration of the structure and the fundamental mode of vibration of the nonstructural component. Where the fundamental period of vibration of the nonstructural element, $T_{N S}$, is close to that of any mode, $i$, of the building, $T_{i}$, dynamic amplification is expected. To represent this amplification a term is used called the Dynamic Amplification Factor, $D A F$. This factor is a function of the ratio of the nonstructural component's fundamental period of vibration to the building's period of vibration of mode $i, r_{T, i}$, given by Equation 2 .

$$
r_{T, i}=\frac{T_{N S}}{T_{i}}
$$

At low period ratios, where the nonstructural component is rigid, there is no dynamic amplification and the acceleration demand is the same as the peak floor acceleration. Near resonance between the modes of vibration of the structure and the fundamental mode of vibration of the nonstructural component the dynamic amplification tends upwards towards a peak at $r_{T, i}=1$. Beyond this, the component is more flexible and the shape decays towards zero.

In this work $D A F$ is modelled as a piecewise function, shown in Figure 2, similar to that defined in the "Alternate Floor Response Spectra" approach in ASCE 7-16 [2]. The shape of DAF) has been modified in this work to have a more narrow amplification peak in the $r_{T, i}$ range between $r_{T, A}$ to $r_{T, D}$ where $D A F>1$. This was based on empirical trial and error of the prediction method verified against the instrumented building records discussed later in this paper. At period ratios beyond the amplification peak $D A F$ was modified from the value of 1 used in ASCE 7-16 [2] to a decay towards zero to more accurately represent the shape observed when a floor acceleration response spectrum is integrated into a floor displacement response spectrum.

As seen in Figure 2, DAF involves a maximum dynamic amplification factor term, $D A F_{\text {max }}$ which varies the peak amplification . This is set as a function of the damping of the nonstructural component, $\xi_{N S}$ (hereinafter called "nonstructural damping") to account for the increased amplification in response expected in less-damped components. There is support in the literature for including $D A F_{\max }$ values for a range of nonstructural damping values back to early contributions to this research [16]. Kehoe and Hachem [1] provide $D A F_{\max }$ at $2 \%$ nonstructural damping, while ASCE 7-16 uses $D A F_{\max }$ set at 5 . The method proposed here uses the maximum dynamic amplification expression of Welch and Sullivan [4], which is dependent on both structural and nonstructural damping, $\xi_{s t r}$ and $\xi_{N S}$, respectively. Including provision for $\xi_{s t r}$ aims to predict the increased dynamic amplification observed for buildings which provide lower struc- 


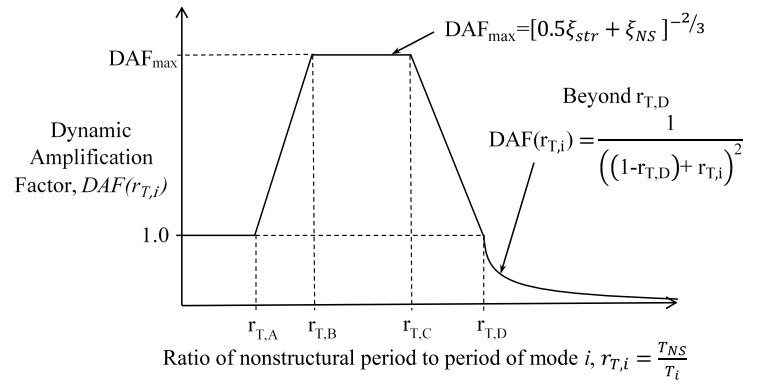

Figure 2: Dynamic Amplification Factor used to compute the contribution of a given mode of vibration of the building to the floor acceleration response spectrum.

tural damping, such as steel frame buildings. It is this therefore this equation that is recommended for use by practitioners. In this paper it is assumed that the predominantly-concrete instrumented buildings can be characterised by $5 \%$ damping. The recommended expression is given in Equation 3:

$$
D A F_{\max }=\left[0.5 \xi_{s t r}+\xi_{N S}\right]^{-2 / 3}
$$

These expressions were empirically derived $[4 ; 7]$ where the dynamic amplification was assessed from floor acceleration response spectra computed from nonlinear time history analyses for a set of ground motions. It should be noted that the accuracy of the proposed method is limited by the significant record-torecord variation in dynamic amplification that was observed in previous studies [4;11], showing uncertainty in the amplification expected.

The shape of $D A F$ is defined by a piecewise function bound by limits defined by period ratios $r_{T, A}$ to $r_{T, D}$. Where $r_{T, i}$ is 0 , the component is rigid and moves with the floor, thus the $D A F\left(r_{T, i}=0\right)$ value of 1 reflects the peak floor acceleration given by $\Gamma_{i} \phi_{i, j} S_{G A}\left(T_{i}, \xi_{s t r}\right)$. The ranges $r_{T, A}$ to $r_{T, B}$ and $r_{T, C}$ to $r_{T, D}$ are linear from a value of 1 to the peak amplification value plateau between $r_{T, B}$ and $r_{T, C}$, following the shape given in ASCE 7-16 [2]. A decay curve for $D A F\left(r_{T, i}>r_{T, D}\right)$ is proposed to provide more accurate floor velocity response spectra and floor displacement response spectra when the acceleration spectrum is converted, as discussed further in a later section titled Conversion to Displacement and Velocity Spectra. The DAF function shown in Figure 2 can be described in equation form as:

$$
D A F= \begin{cases}1 & r_{T, i} \leq r_{T, A} \\ \frac{r_{T, i}-r_{T, A}}{r_{T, B}-r_{T, A}}\left(D A F_{\max }-1\right)+1 & r_{T, A}<r_{T, i}<r_{T, B} \\ D A F_{\max } & r_{T, B} \leq r_{T, i} \leq r_{T, C} \\ \frac{r_{T, i}-r_{T, C}}{r_{T, D}-r_{T, C}}\left(1-D A F_{\max }\right)+D A F_{\max } & r_{T, C}<r_{T, i}<T, D \\ \frac{1}{\left(\left(1-r_{T, D}\right)+r_{T, i}\right)^{2}} & r_{T, D} \leq r_{T, i}\end{cases}
$$

The values of $r_{T, A}$ to $r_{T, D}$ define the width of the DAF shape. Broad ranges of period ratios are recommended considering the uncertainty in the periods of vibration of the supporting structure and the fundamental period of the nonstructural element. The amplification peaks in elastic floor acceleration response spectra are often narrow, however, and the use of broad values, such as those prescribed by ASCE 7-16, could be conservative. This work attempts to find a balance by retaining a broad plateau at $D A F_{\text {max }}$ while narrowing the period ratios used in ASCE 716. The period ratios adopted in this work are compared with those from ASCE 7-16 in Table 1. As will be shown later, the values shown in Table 1 were found to provide reasonably good estimates. Where there is only low certainty in the prediction of the periods of vibration of the structure, broader peaks would be required. Optimising these period ratio values to vary based upon the certainty of simplified approaches could be an area for further research.

Table 1: Period ratios used to define DAF shape.

\begin{tabular}{ccccc}
\hline Peak Width & $r_{T, A}$ & $r_{T, B}$ & $r_{T, C}$ & $r_{T, D}$ \\
\hline ASCE 7-16 & 0.5 & 0.75 & 1.25 & 2.0 \\
Adopted & 0.6 & 0.8 & 1.2 & 1.6
\end{tabular}

\section{Combination of Modal Contributions}

The floor acceleration response spectrum at the floor level $j$, $S_{F A, j}$, is defined by taking the maximum value of the SRSS combination of the modal acceleration contributions computed using Equation 1, at each nonstructural period, $S_{F A, i, j}\left(T_{N S}, \xi_{N S}\right)$, and the ground acceleration response spectrum (GRS), $S_{G A}\left(T_{N S}, \xi_{N S}\right)$, as given by Equation 5 :

$$
S_{F A, j}=\max \left[\sqrt{\sum_{i} S_{F A, i, j}\left(T_{N S}, \xi_{N S}\right)^{2}}, S_{G A}\left(T_{N S}, \xi_{N S}\right)\right]
$$

This is illustrated in Figure 3, where each of the modal contributions, ground acceleration response spectrum, and combined floor acceleration response spectrum are shown. A minimum of three modes in each fundamental direction is recommended, where fourth and fifth modes should be considered for buildings with long fundamental periods $[1 ; 2]$. It is common that nonstructural components can be thought of as rigid where the nonstructural component period less than $0.06 \mathrm{~s}$ [17]. It is therefore recommended that structural modes with periods below $0.06 \mathrm{~s}$ do not need to be considered.

Taking the SRSS of modal contributions has been widely proposed $[3 ; 4 ; 14]$. This was adopted herein instead of the maximum of each contribution, as used in Kehoe and Hachem and ASCE 7-16 [1; 2], as it provided better peak floor acceleration predictions for structures with significant higher mode contributions. This approach is thought to balance better predictions with simplicity, contrasted to taking the maximums of the contributions or using the complete-quadratic-combination (CQC) method [3; 14].

Taking the maximum of combined modes and the ground acceleration response spectrum has been widely adopted [1-4]. The use of the ground response spectrum is supported by the notion of rigid body motion discussed in Pozzi and Der Kiureghian [18], where it was observed that lower levels of the structure do not filter the ground acceleration response spectrum as upper levels do, retaining the same spectral shape. There is some evidence in the floor acceleration response spectra computed from the instrumented building records that even at upper levels the ground acceleration response spectrum demands are still present due to rigid body motion of the building. For simplicity, the maximum of the ground acceleration response spectrum and the modal contributions are taken for any floor, $j$, in the building.

\section{Nonstructural Component Damping}

Several studies have recognised the importance of incorporating the influence of damping of the nonstructural component, $\xi_{N S}$, into floor acceleration response spectrum prediction methods $[3 ; 4 ; 7 ; 11 ; 14]$. Significant amplification of the modal peaks 


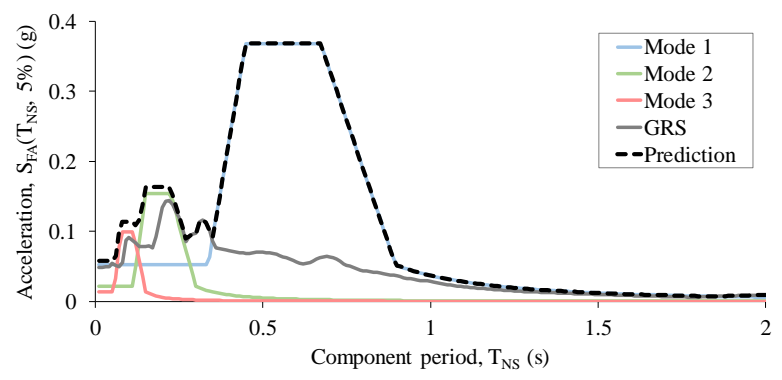

Figure 3: Combination of modal contributions of modes 1,2, and 3, with the ground acceleration response spectrum (GRS) to determine floor acceleration spectrum at floor 4 of the UC Physics building for the longitudinal direction in the M4.8 October 2010 earthquake.

within the response spectra at lower damping values has been repeatedly observed.

Quantifying the nonstructural damping without testing poses a challenge for design. Empirical data has been gathered through relatively simple testing using accelerometers and impact hammers [19]. Despite this, the research on nonstructural damping is still sparse for many components, particularly at the high intensities of design interest where damping is assumed to be greater [11]. Rigid components, such as machinery, are likely to have low damping and, therefore, the assumption of a nonstructural damping ratio of $5 \%$ would lead to under-prediction of the floor acceleration response spectrum demands. The work presented in this paper uses nonstructural damping ratios, $\xi_{N S}$, of $2 \%$ and $5 \%$. Further research into component damping is proposed for greater confidence in the use of floor spectra as a design basis.

Two ground acceleration response spectra are required to predict floor acceleration response spectrum using the proposed method, one of which is the site-specific ground acceleration response spectrum scaled to the damping of the structure, $S_{G A}\left(T, \xi_{s t r}\right)$. As noted earlier, $\xi_{s t r}=5 \%$ is used for all modes to maintain simplicity, as this is a common assumption for many buildings. This spectrum corresponds to the unscaled design ground acceleration response spectrum specified in codes such as NZS1170.5 [20]. This recommendation follows the conclusion by ATC that damping of the structure does not play a large role in component response [11]. This spectrum is used to assess the spectral acceleration of each of the modes, $S_{G A}\left(T_{i}, \xi_{s t r}\right)$ which is used to create the peak floor acceleration in Equation 1.

The second spectrum required is the site-specific ground acceleration response spectrum scaled to the damping of the nonstructural component, $S_{G A}\left(T_{N S}, \xi_{N S}\right)$ used in Equation 5. This corresponds to the amplification expected from the component responding to the rigid body motion of the building not filtering the ground acceleration response spectrum. This is assessed by multiplying the 5\%-damped design ground response spectrum by a scaling factor, $\eta$. Several empirical expressions for $\eta$ exist, such as that given in Equation 6 from Eurocode 8 [21], where $\xi$ is the nonstructural damping value of interest, given as a percentage.

$$
\eta=\sqrt{\frac{10}{5+\xi}} \geq 0.55
$$

If the floor acceleration response spectrum is required for a specific earthquake ground motion, ground acceleration response spectra should be produced at both at $5 \%$ structural damping and at the nonstructural damping level of interest as required. This was undertaken in this work for the verification of the prediction method using the records from instrumented structures, as discussed later in this paper.

\section{Nonstructural Component Period}

The period of the nonstructural component, $T_{N S}$, is the dependant variable for assessing demands using floor response spectra. Nonstructural components are assumed to be simple single-degreeof-freedom (SDOF) oscillators with a vibrational period, though this may not always be valid. Components themselves can be complex and may have complex interactions with bracing and supports. The commentary to NZS1170.5 [20] recommends testing or analysis of the component to establish the period. Kehoe [17] notes, however, that this is rarely the case in practice due to these complexities. Further, as discussed by Kehoe [17], the vibration characteristics of components found through testing only represents a small fraction of available components. Nonstructural period elongation may also occur due to softening, which risks lengthening the period into resonant behaviour with the structural modes. The influence of this on the floor response spectrum, as well as the associated ductile response of the component, is beyond the scope of this work and is a possible area of future research.

In this work, floor response spectra are generated which account for uncertainty in the fundamental period of the structure, $T_{1}$, but not the component period, $T_{N S}$. This results in floor acceleration response spectra with peaks and troughs over small period intervals. It is cautioned that over-prescription of the component period to capture troughs may result in unrealistic predictions of design accelerations. It is therefore recommended that the floor response spectra generated using this proposed method is used with cautious consideration of uncertainty of the component period. There is an opportunity for further work to refine this method to avoid these potential issues.

\section{Conversion to Displacement and Velocity Spectra}

Displacement or velocity sensitive components may be designed using elastic floor response spectral analysis. This work makes explicit consideration to the derivation of these spectra from the floor acceleration response spectrum prediction. To convert from a floor acceleration response spectrum at floor $j$, given in absolute acceleration as $S_{F A, j}$, to a floor velocity response spectrum, $S_{F V, j}$ or a floor displacement response spectrum $S_{F D, j}$, given relative to the floor, Equations 7 and 8 are used, respectively.

$$
\begin{gathered}
S_{F V, j}=\frac{S_{F A, j} T_{N S}}{2 \pi} \\
S_{F D, j}=\frac{S_{F A, j} T_{N S^{2}}}{4 \pi^{2}}
\end{gathered}
$$

The amplification shape for any given mode, $i$, in a floor velocity response spectrum, $S_{F V, i, j}$, and a floor displacement response spectrum, $S_{F D, i, j}$, can be seen in Figure 4, where the spectra are normalised by a unit value of peak floor acceleration (PFA). This aims to closely match the spectral shapes observed from recorded floor velocity response spectra and floor displacement response spectra.

\section{Recommendations Aimed at Maintaining a Simplified Ap- proach}

Given that the approach requires characterisation of various modal parameters, efforts are made to enable easy practical use of the approach through simplified mode shape and building period estimates. 


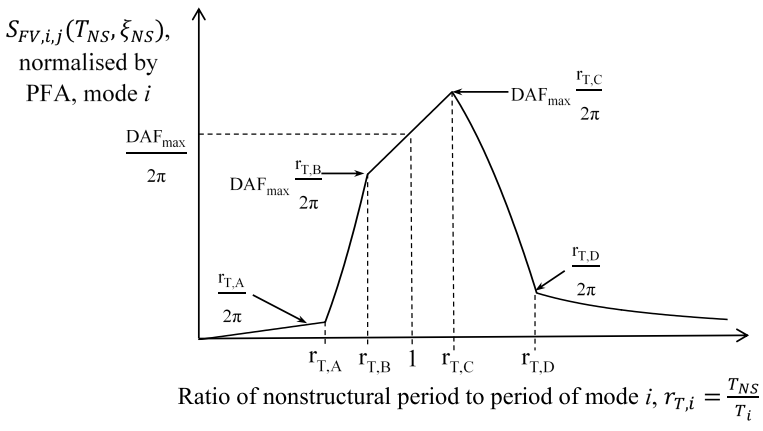

(a) PFA-normalised velocity spectrum for mode $i$.

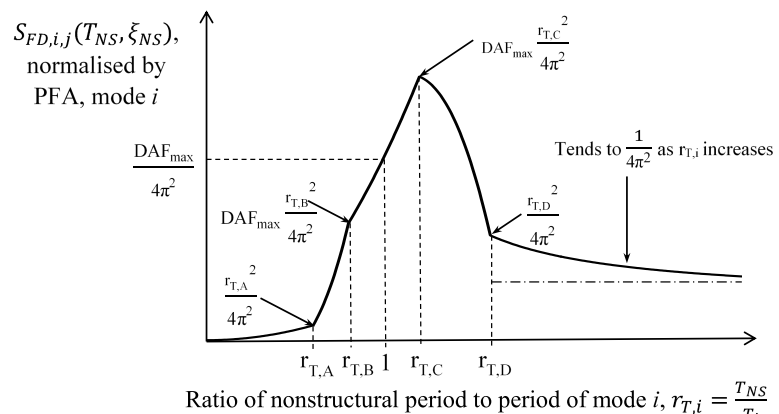

(b) PFA-normalised displacement spectrum for mode $i$.

Figure 4: Modal components of the velocity and displacement spectra generated by a unit value for peak floor acceleration (PFA).

\section{Fundamental Period of Vibration of the Building}

The fundamental period of vibration of the building in the direction of interest, $T_{1}$, is a key parameter in the determination of floor acceleration response spectra. Significant dynamic amplification of acceleration, velocity, and displacement floor response spectra around the fundamental period of vibration has been widely observed [3; 11]. Accurate estimation of the fundamental period of vibration is important to obtain accurate predictions with any method that uses modal superposition to predict floor acceleration response spectra. It is recognised that there is uncertainty in estimating $T_{1}$. It is the intention that this uncertainty is captured by the broadness of the plateau at the maximum value of the dynamic amplification factor (DAF), as shown in Figure 2.

Simplified methods for determining $T_{1}$ would help to enable easy use of the proposed method. A means for this may be the empirical approaches for estimating $T_{1}$ that are available in many codes, such as the commentary of NZS1170.5 [20], ASCE 7-16 [2], and Eurocode 8 [21]. These empirical methods use the structural typology of the lateral force resisting system and the total height of the structure. The potential impact of using these methods will be reviewed herein with reference to the floor acceleration response spectra of instrumented structures.

\section{Higher Modes of Vibration}

It has been observed from numerical models and instrumented structures that responses of higher modes of vibration of a building (hereinafter called "higher modes") can make considerable contributions to the demands described by a floor acceleration response spectrum $[3 ; 4 ; 7 ; 13 ; 14 ; 22]$. There is value in generating more accurate predictions for the higher mode periods, $T_{H M}$, as this changes the placement along the $\mathrm{x}$-axis of the high mode contributions to the floor acceleration response spectrum and the ground acceleration response spectral ordinate, $S_{G A}\left(T_{H M}, \xi_{s t r}\right)$. Better period estimations will directly decrease the uncertainty of floor spectrum predictions in the shorter period range. This effect is most pronounced in floor acceleration response spectra as floor displacement response spectra are often dominated by the response of the fundamental mode [15].

It is recommended that values for higher mode periods from eigenvalue analysis be used where available. In this work, values for higher mode periods, $T_{H M}$, were determined for each direction of the instrumented buildings by multiplying the fundamental period of vibration, $T_{1}$, assessed using frequency response functions, with standard ratios for $T_{H M} / T_{1}$ defined for given lateral force resisting typologies, as given in Table 2 . These were used to investigate the sensitivity of the floor acceleration response spectra predictions to simplified approaches.
Table 2: Simplified higher mode ratios used for a simplified implementation of the prediction method.

\begin{tabular}{ccc}
\hline Typology & $T_{2} / T_{1}$ & $T_{3} / T_{1}$ \\
\hline Wall & $1 / 5$ & $1 / 10$ \\
Frame & $1 / 3$ & $1 / 6$ \\
\hline
\end{tabular}

The contribution of mode $i$, at floor $j$, to the floor acceleration response spectrum, given by Equation 1, involves using the product of the modal participation factor and mode shape, $\Gamma_{i} \phi_{i, j}$. It is recommended that values for modal participation factors and mode shapes from eigenvalue analysis be used where available.

It was found in this study that the accuracy of the mode shape does not make a significant contribution to the accuracy of the floor acceleration response spectrum. The simplified approach in Miranda and Taghavi [23] is therefore recommended in lieu of modal analysis results, where the typology of the lateral force resisting structure in the direction of interest is the only parameter, assuming constant lateral stiffness at all building heights. In this work, values for the dimensionless parameter $\alpha_{0}$ which controls the degree of participation of overall flexural and overall shear deformations in Miranda and Taghavi [23] were taken as 12.5 for moment resisting frame structures and 1.25 for shear wall structures corresponding to the average value for these typologies given in their work.

The participation factor for each mode $i, \Gamma_{i}$, can be computed using Equation 9:

$$
\Gamma_{i}=\frac{\Phi_{i}^{T}[M]}{\Phi_{i}^{T}[M] \Phi_{i}}
$$

where $\Phi_{i}=$ mode shape vector for mode $i$ at all floors; and $\mathrm{M}=$ global mass matrix.

This may be further simplified where the masses of the floors can be assumed to approximately equal, as was assumed in this work, to reduce to Equation 10:

$$
\Gamma_{i}=\frac{\sum \phi_{i, j}}{\sum \phi_{i, j}^{2}}
$$

where $\phi_{i, j}$ is the mode shape of mode $i$ at floor $j$.

To enable easy adoption of the method outlined in this paper, values for the mode shapes and participation factors for modes 1,2 , and 3 at each floor for structures between 1 and 20 storeys, along with the corresponding participation factors, are given in Appendix A. These values were computed using the method proposed in Miranda and Taghavi [23] with an $\alpha_{0}$ value of 3.125. 
This corresponds to the average for dual moment resisting frame and wall structures which is thought to be sufficiently representative of typical building structures for the use of this simplified method.

\section{Floor Diaphragm Flexibility and Torsion}

The floor and roof diaphragms were assumed to be rigid. Variation of demands due to diaphragm flexibility is assumed negligible and thus the predictions generated using the proposed method do not vary horizontally across the floor. ATC [11] (amongst others) report that significant amplification can be produced at the midspan of flexible diaphragms, and at the perimeter of torsionally sensitive structures with rigid diaphragms. However, they concluded that the complexity required in a prediction method to account for this is beyond the scope of a simplified method. Likewise, building irregularities were deemed too complex to model using a simplified method, and should be accounted for using a more rigorous method such as time-history analysis.

\section{VALIDATION OF THE PREDICTION METHOD USING OBSERVED DATA}

To validate the performance of the proposed method, floor acceleration response spectra and floor displacement response spectra were predicted and compared with data from instrumented buildings in New Zealand recorded in recent earthquakes. The buildings identified for this purpose form part of the GeoNet Structural Array [5]. The structures examined in this research are the two seismically-separated Avalon GNS buildings (Units 1 and 2), the BNZ CentrePort Harbour Quays building, the University of Canterbury Physics (UC Physics) building, and the MBIE Stout St building, a summary of which can be seen in Table 3. In each building the longitudinal and transverse responses were recorded at each instrumented floor by triaxial accelerometers. Further information on the instrumentation can be found at GeoNet [5].

The UC Physics building recorded motions from the 2010/2011 Canterbury earthquake sequence (M4.7 to M6.3), where minor cracking of the concrete structure was observed [24]. The GNS and BNZ buildings recorded motions in the 2013 Seddon (M6.5) and Grassmere (M6.6) earthquakes. In these events significant nonstructural damage was observed in the BNZ building [25]. The 2016 M7.8 Kaikōura earthquake motions were recorded by the GNS, MBIE and BNZ buildings. The BNZ building experienced structural damage in this earthquake and is being demolished at the time of this paper. All other buildings are assumed to have remained within the elastic range. All motions examined in this work are from earthquakes with far-field epicentres.

The intensity of the events examined can be contextualised with the 5\% damped ground acceleration response spectra in the longitudinal and transverse axes of the buildings used are plotted in Figure 5. The fundamental periods in each of the orthogonal directions, taken as the mean from the values inferred from the frequency response functions (discussed below) are identified in the figure. The 500-year return period Ultimate Limit State (ULS) and 25-year return period Serviceability Limit State (SLS) intensity design ground acceleration response spectra are also plotted in Figure 5, as prescribed in NZS1170.5:2004 [20] and NZS1170.0:2002 [26] assuming a 50-year design life at importance level 2. It should be noted that all buildings except the BNZ CentrePort building were designed prior to current standards, which came into effect in 2004, and thus these spectra are provided merely for context. The intensities of the events experienced by the UC Physics and Avalon GNS buildings appear to be approximately at or below the SLS intensity level. The MBIE Stout St building experienced shaking above SLS intensity and below ULS intensity. In the Kaikōura 2016 earthquake the BNZ building experienced shaking similar to ULS intensity.

\section{Processing of Accelerometer Data}

Accelerograms were downloaded from the GeoNet server and extracted into the recorded $\mathrm{x}, \mathrm{y}$ and $\mathrm{z}$ directions. The records in the horizontal directions were reoriented from the recorded orientation of the instruments to longitudinal and transverse axes of the building. Any static offsets in the recordings were removed. The accelerograms were zero-padded and filtered using acausal fourth-order Butterworth filters with corner frequencies of $0.1 \mathrm{~Hz}$ and $20 \mathrm{~Hz}$, following the procedure employed by Chandramohan et al. [25].

One accelerogram for each orthogonal direction was calculated per floor in each event. To infer responses at points across the floor it was assumed that the floors behaved as rigid diaphragms. At a floor where three linearly independent measurements were recorded, the torsional response of the building was calculated and removed from the longitudinal and transverse accelerograms. At a floor where only two linearly independent recordings were available, the longitudinal and transverse accelerograms were taken directly from the processed measurements. Where the number of linearly independent measurements exceeded three, however, the system was overdefined, and a least squares approach was required. The least squares approach was used for the UC Physics and Avalon GNS buildings to compute records at the geometric centre of the floor. Accelerometers on the southwest wall of BNZ building were used, where the longitudinal and transverse floor records were taken directly from the processed accelerograms and the torsional response was neglected due to the sparsity of instrumentation.

\section{Assessment of Structural Properties}

Fundamental periods of vibration in each horizontal direction were inferred from peaks in frequency response functions, computed as the ratio of the Fourier amplitude spectrum at each instrumented storey to the Fourier amplitude spectrum at the

Table 3: Overview of GeoNet instrumented buildings used as case studies.

\begin{tabular}{cccccccc}
\hline Building & Location & Storeys & Lateral load resisting sytem & $\begin{array}{c}\text { Year } \\
\text { built }\end{array}$ & $\begin{array}{c}\text { Year } \\
\text { instr.ed }\end{array}$ & $\begin{array}{c}\text { Floors } \\
\text { instr.ed }\end{array}$ & $\begin{array}{c}\text { Instruments } \\
\text { available }\end{array}$ \\
\hline UC Physics & Christchurch & 8 & Coupled RC shear walls & 1961 & 2007 & 3 & 10 \\
Avalon GNS U1 & Lower Hutt & 3 & RC MRF & 1973 & 2007 & 1 & 4 \\
Avalon GNS U2 & Lower Hutt & 3 & RC MRF & 1973 & 2007 & 2 & 5 \\
BNZ CentrePort & Wellington & 5 & RC MRF & 2009 & 2009 & 5 & 14 \\
MBIE Stout St & Wellington & 9 & Concrete-encased steel MRF & 1940 & 2014 & 9 & 16 \\
\hline
\end{tabular}




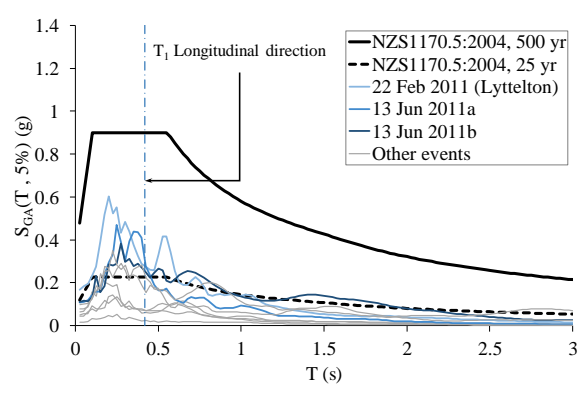

(a) UC Physics - Longitudinal Direction.

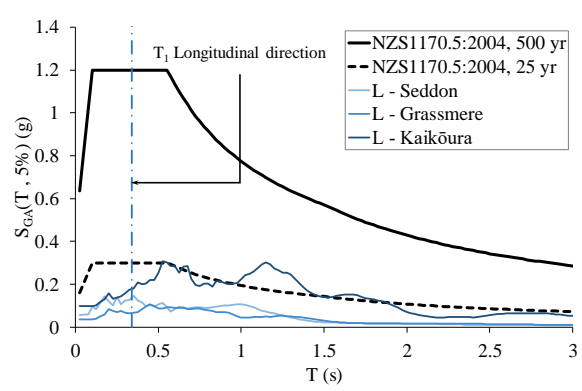

(c) Avalon GNS Unit 1 - Longitudinal Direction.

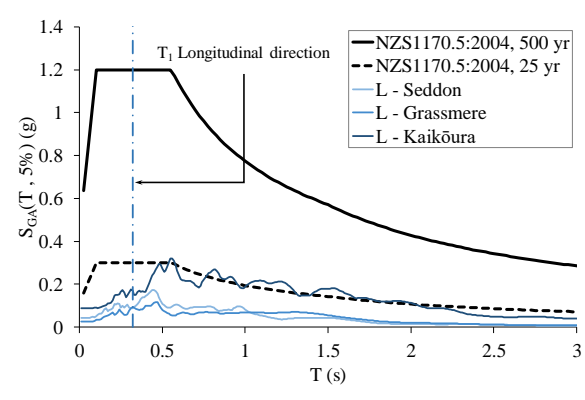

(e) Avalon GNS Unit 2 - Longitudinal Direction.

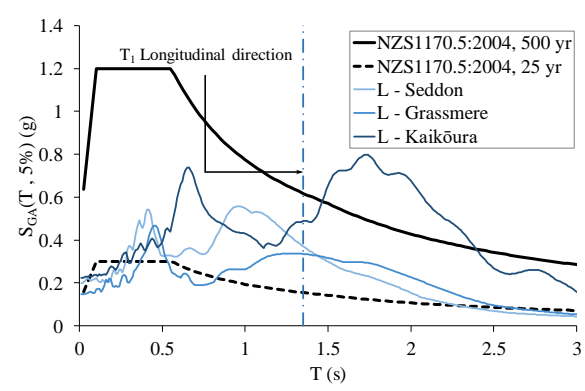

(g) BNZ CentrePort - Longitudinal Direction.

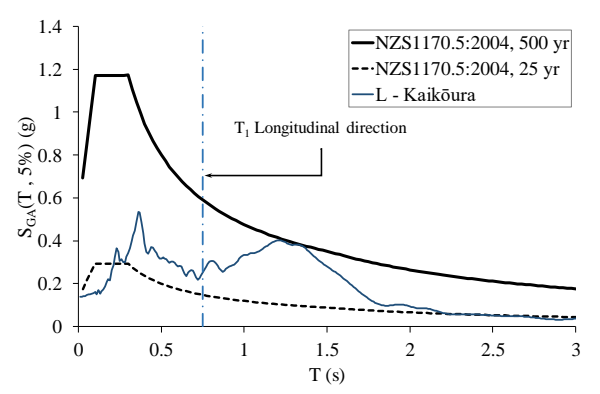

(i) MBIE Stout St - Longitudinal Direction.

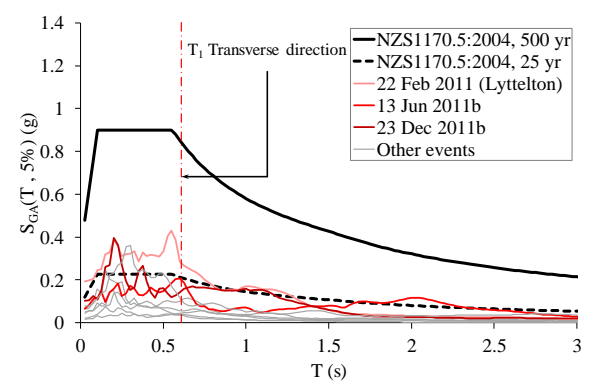

(b) UC Physics - Transverse Direction.

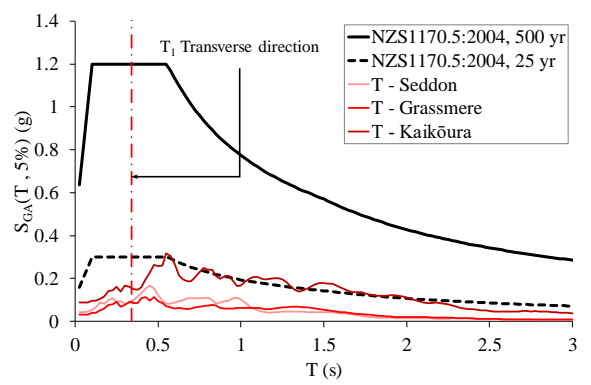

(d) Avalon GNS Unit 1 - Transverse Direction.

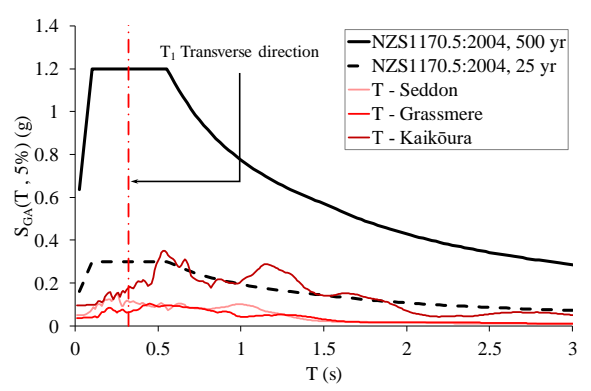

(f) Avalon GNS Unit 2 - Transverse Direction.

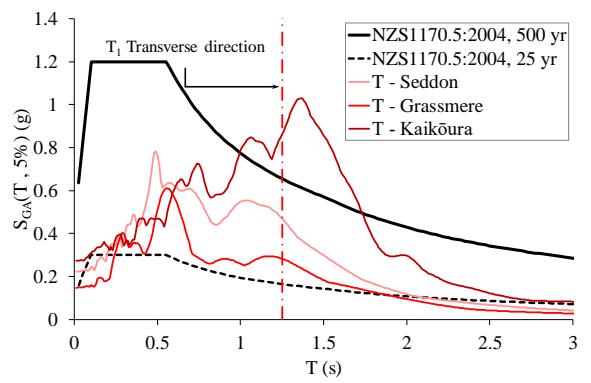

(h) BNZ CentrePort - Transverse Direction.

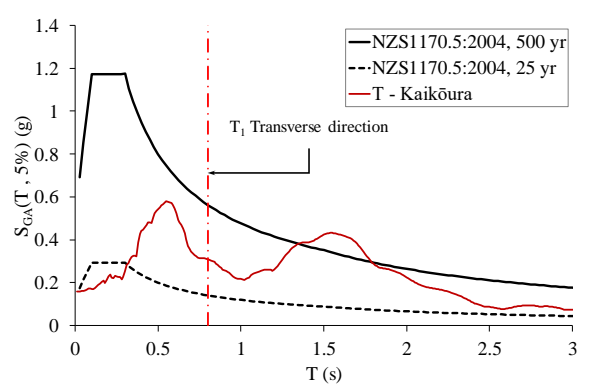

(j) MBIE Stout St - Transverse Direction.

Figure 5: Acceleration response spectra from accelerograms recorded at ground level of the instrumented buildings. 
Table 4: Fundamental periods (s) in orthogonal directions in events studied, as inferred from frequency response functions.

\begin{tabular}{|c|c|c|c|c|c|c|c|c|c|c|}
\hline \multirow[b]{2}{*}{ Event } & \multicolumn{2}{|c|}{ UC Physics } & \multicolumn{2}{|c|}{ Avalon GNS U1 } & \multicolumn{2}{|c|}{ Avalon GNS U2 } & \multicolumn{2}{|c|}{ BNZ CentrePort } & \multicolumn{2}{|c|}{ MBIE Stout St } \\
\hline & Long & Trans & Long & Trans & Long & Trans & Long & Trans & Long & Trans \\
\hline M4.8 - 19 Oct 2010 & 0.41 & 0.56 & - & - & - & - & - & - & - & - \\
\hline M4.7 - 26 Dec 2010 & 0.39 & 0.58 & - & - & - & - & - & - & - & - \\
\hline M6.3 - 22 Feb 2011 (Lyttelton) & 0.46 & 0.63 & - & - & - & - & - & - & - & - \\
\hline M5.0 - 16 Apr 2011 & 0.41 & 0.55 & - & - & - & - & - & - & - & - \\
\hline M5.3 - 13 Jun 2011a & 0.47 & 0.58 & - & - & - & - & - & - & - & - \\
\hline M6.0 - 13 Jun 2011b & 0.46 & 0.59 & - & - & - & - & - & - & - & - \\
\hline M4.9 - 09 Oct 2011 & 0.40 & 0.59 & - & - & - & - & - & - & - & - \\
\hline M5.8 - 23 Dec 2011a & 0.45 & 0.61 & - & - & - & - & - & - & - & - \\
\hline M5.9 - 23 Dec 2011b & 0.44 & 0.63 & - & - & - & - & - & - & - & - \\
\hline M6.5 - 21 Jul 2013 (Seddon) & - & - & 0.34 & 0.39 & 0.32 & 0.37 & 1.00 & 1.10 & - & - \\
\hline M6.6 - 16 Aug 2013 (Grassmere) & - & - & 0.33 & 0.40 & 0.32 & 0.37 & 1.30 & 1.20 & - & - \\
\hline M7.8 - 14 Nov 2016 (Kaikōura) & - & - & 0.35 & 0.39 & 0.34 & 0.39 & 1.50 & 1.40 & 0.75 & 0.80 \\
\hline
\end{tabular}

ground. This is illustrated in Figure 6 where the roof motions of the Avalon GNS Unit 2 building from the 2013 M6.5 Seddon earthquake were used, and the peak corresponding to the fundamental mode of vibration is identified. A summary of the fundamental periods inferred is presented in Table 4 .

The ground spectral accelerations were computed for each mode, $S_{G A}\left(T_{i}, \xi_{s t r}\right)$, from the ground acceleration response spectrum recorded at the ground level in each orthogonal direction. This is illustrated in Figure 7 using the Avalon GNS Unit 2 building ground acceleration response spectra from the 2013 M6.5 Seddon earthquake, where each of the periods of vibration are indicated.

\section{COMPARISON OF OBSERVED AND PREDICTED FLOOR RESPONSE SPECTRA}

A floor acceleration response spectrum was computed in the longitudinal and transverse directions at each floor where data was available. This was done by stepping through the accelerogram processed in one orthogonal direction at a floor, solving the equation of motion for series of SDOF oscillators with different periods with a given nonstructural damping value, and taking the maximum acceleration responses.

The floor acceleration response spectra examined herein have similar characteristics and are thought to be representative of the form of most floor acceleration response spectra. At very low periods, below $0.1 \mathrm{~s}$, the spectral acceleration approaches the peak floor acceleration of the structure. Above $0.1 \mathrm{~s}$, peaks in spectral acceleration from superposition of modes can be observed around the periods of vibration of the structure. At places the floor acceleration response spectrum is similar to the ground acceleration response spectrum due to rigid body motion of the structure. This often dominates the floor acceleration response spectrum beyond the peak due to the fundamental mode of vibration of the structure, which is best observed in a floor displacement response spectrum.

The performance of the prediction method is assessed through comparison of the observed spectra to those predicted using the recorded ground acceleration response spectra. To illustrate this, Figure 8 compares the floor acceleration response spectra and floor displacement response spectra predicted and recorded in the MBIE Stout St building during the M7.8 Kaikōura 2016 earthquake. This figure shows the floor acceleration response spectra and floor displacement response spectra in the longitudinal direction at floors 1,3,6, and 9, at 2\% and 5\% nonstructural damping. Ground acceleration and displacement response spectra in the longitudinal direction are also plotted at $2 \%$ and $5 \%$ nonstructural damping.

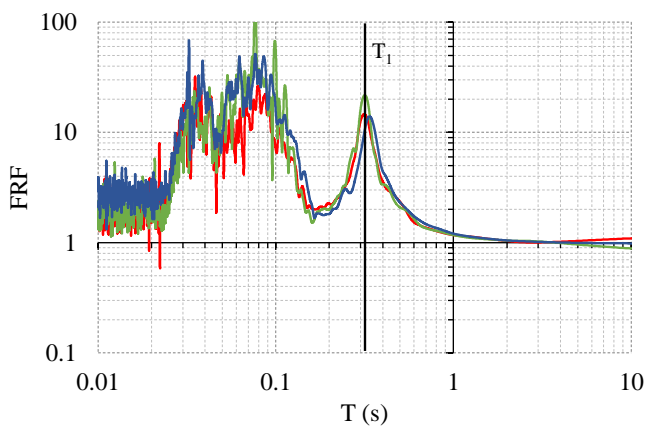

(a) Longitudinal Direction.

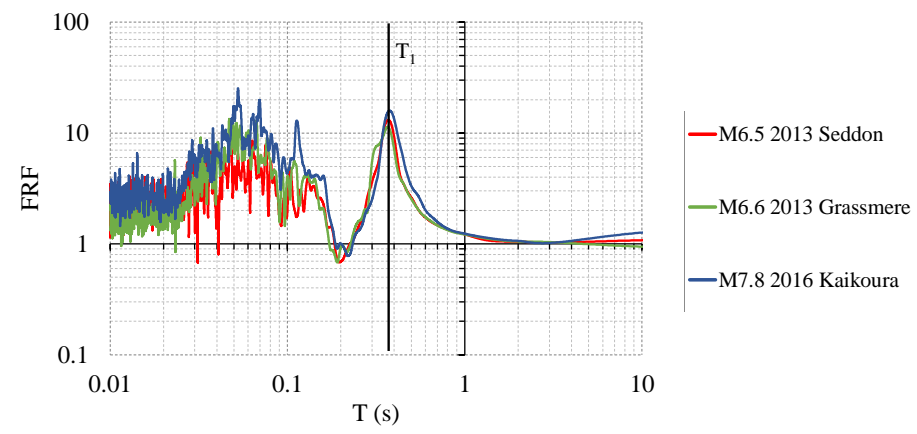

(b) Transverse Direction.

Figure 6: Frequency response functions (FRF) computed from the Avalon GNS Unit 2 building's roof motions from the 2013 Seddon, 2013 Grassmere, and 2016 Kaikoura earthquake records with the fundamental period in the longitudinal and transverse directions inferred from peaks. 


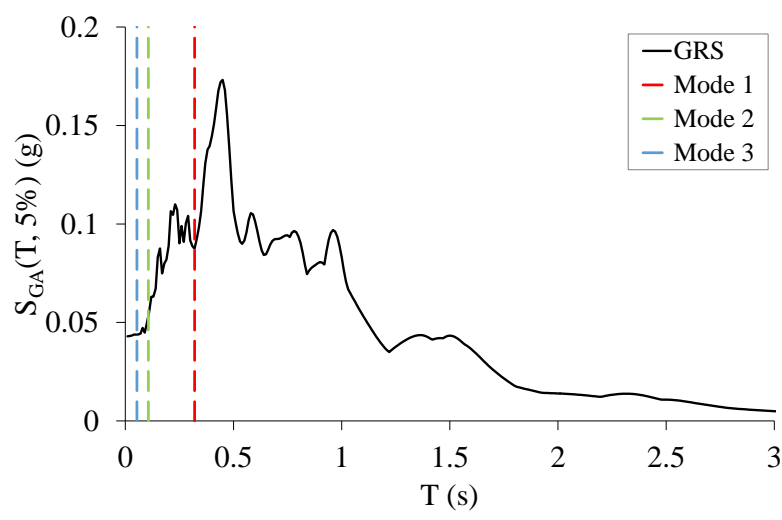

(a) Longitudinal Direction.

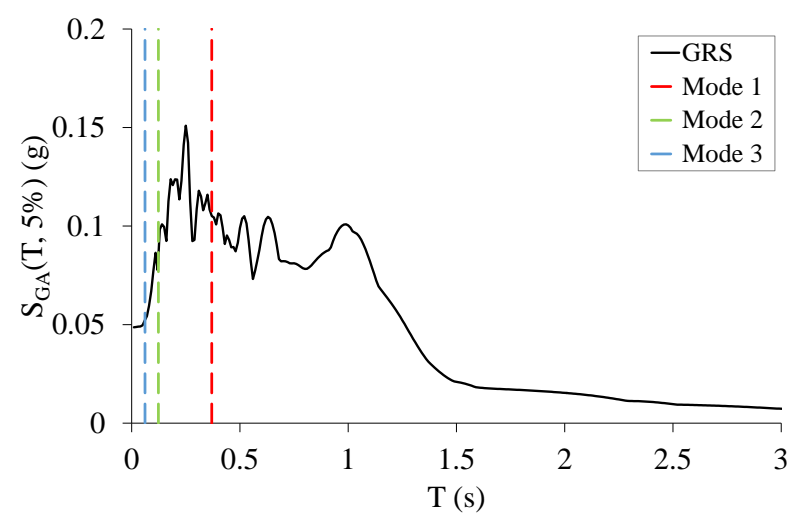

(b) Transverse Direction.

Figure 7: Input $S_{G A}\left(T_{i}\right)$ values found for the first three modes of the Avalon GNS Unit 2 building from the ground response spectra (GRS) recorded in the 2013 Seddon earthquake.

Table 5: Comparison between values for the fundamental period of vibration, $T_{1}$, given by the commentary of NZS1170.5 and by the frequency response function, FRF, where the structure performs at or below the serviceability limit state intensity, $S L S$, as given in NZS1170.0.

\begin{tabular}{ccccc}
\hline & \multicolumn{2}{c}{ Longitudinal } & \multicolumn{2}{c}{ Transverse } \\
Building & $\begin{array}{c}\text { NZS1170.5 } \\
\text { Simplified }\end{array}$ & $\begin{array}{c}\text { Average } \\
\text { Elastic FRF }\end{array}$ & $\begin{array}{c}\text { NZS1170.5 } \\
\text { Simplified }\end{array}$ & $\begin{array}{c}\text { Average } \\
\text { Elastic FRF }\end{array}$ \\
\hline UC Physics & $T_{1}=0.65 \mathrm{~s}$ & $T_{1}=0.42 \mathrm{~s}$ & $T_{1}=0.65 \mathrm{~s}$ & $T_{1}=0.60 \mathrm{~s}$ \\
Avalon GNS Unit 1 & $T_{1}=0.44 \mathrm{~s}$ & $T_{1}=0.34 \mathrm{~s}$ & $T_{1}=0.44 \mathrm{~s}$ & $T_{1}=0.39 \mathrm{~s}$ \\
Avalon GNS Unit 2 & $T_{1}=0.44 \mathrm{~s}$ & $T_{1}=0.33 \mathrm{~s}$ & $T_{1}=0.44 \mathrm{~s}$ & $T_{1}=0.38 \mathrm{~s}$ \\
BNZ CentrePort & $T_{1}=0.80 \mathrm{~s}$ & $T_{1}=1.00 \mathrm{~s}$ & $T_{1}=0.80 \mathrm{~s}$ & $T_{1}=1.10 \mathrm{~s}$ \\
MBIE Stout St & $T_{1}=1.04 \mathrm{~s}$ & $T_{1}=0.75 \mathrm{~s}$ & $T_{1}=1.04 \mathrm{~s}$ & $T_{1}=0.85 \mathrm{~s}$ \\
\hline
\end{tabular}

Figure 8 shows that the proposed method provides floor acceleration response spectra and floor displacement response spectra predictions that are similar to those observed from the instrumented floor records. The position of the prediction modal contributions are close to the periods of the observed corresponding peaks. The predicted spectral acceleration of the fundamental mode contribution was similar to that in the observed spectra, although the predicted spectral acceleration of higher mode contributions was not. At long periods, greater than $2 \mathrm{~s}$, the prediction closely matches the observed data, as this is where rigid body motion dominates.

The influence of the mode shapes on floor acceleration response spectra can be observed in the recorded spectra in Figure 8 by comparing the peaks in spectral acceleration around the periods of vibration of the structure at different floors. The mode shape of the fundamental mode is observed by the significant increase in spectral acceleration with floor height between periods $T_{N S}$ $=0 \mathrm{~s}$ to $2 \mathrm{~s}$. The influence of higher modes can be observed between approximately $T_{N S}=0.1 \mathrm{~s}$ to $0.5 \mathrm{~s}$. The shape of the second mode response is observed by comparing the floor acceleration response spectra at the period range of approximately $T_{N S}=0.3 \mathrm{~s}$ to $0.5 \mathrm{~s}$. The shape of the second mode implies that higher spectral accelerations should be expected in this range at approximately one-third of the building height and at the roof, with a lower amplitude at two-thirds of the building height. This is observed in the peaks in spectral acceleration in the floor acceleration response spectra of floors 3 and 9 , and the absence of the peak in the floor acceleration response spectra of floor 6 .

Recall that the proposed floor spectrum method makes explicit consideration of the width of amplification peaks using the DAF with the period ratios $r_{T, A}$ to $r_{T, D}$. Examining the contribution of the fundamental mode to the floor acceleration response spectra in Figure 8, it appears the first regions of the DAF, the flat and linear-increase shapes, fit well with the amplification observed from the recorded spectra. This implies $r_{T, A}$ and $r_{T, B}$ are well located. It can further be seen that the proposed plateau is sufficiently broad enough to capture the peak intensity of the amplification of spectral acceleration due to the fundamental mode. At periods greater than the fundamental period of the building (between $1 \mathrm{~s}$ and $2 \mathrm{~s}$ ) there is, however, significant amplification of spectral acceleration that is not well captured by the prediction method. This may imply that $r_{T, D}$ should be at a longer period ratio to widen the linear decay shape if this response corresponds to amplification due to the fundamental mode. It may, however, be a torsional response that this work has not accounted for. This observation was not made in all cases, however. As seen later, Figure 10 shows that the width of the DAF defined by the period ratios used in this work predicts a floor acceleration response spectrum that fits well to the spectrum observed at the roof level of the UC Physics building in the Lyttelton earthquake. These observations evidence that further work to define the period ratios may be required.

The floor acceleration response spectrum at floor 1 in Figure 8 shows no signification variation from the ground acceleration response spectrum. This characterises the rigid body motion of lower levels in the building observed in prior studies [4; 18]. This observation supports constructing the predicted floor acceleration response spectrum using the maximum of both the combined modal response and the ground acceleration response spectrum.

The influence of rigid body motion on floor acceleration response 


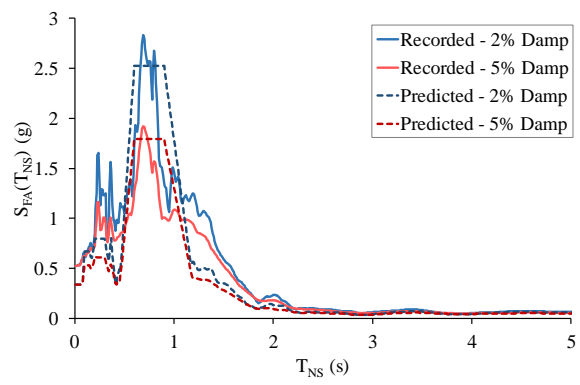

(a) Acceleration FRS - Floor 9.

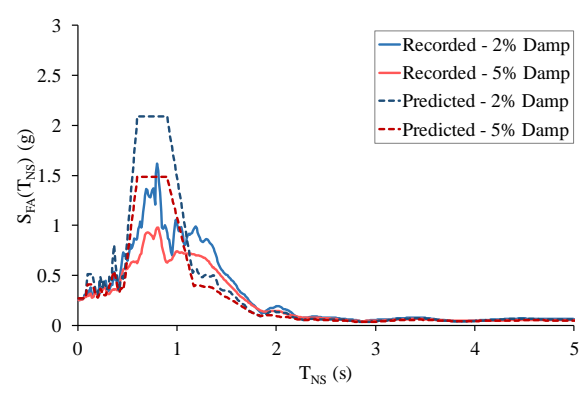

(c) Acceleration FRS - Floor 6 .

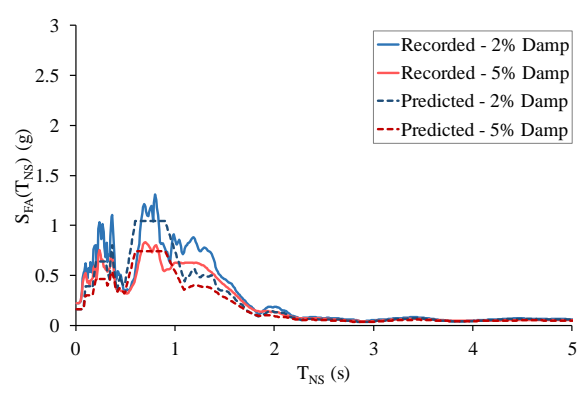

(e) Acceleration FRS - Floor 3.

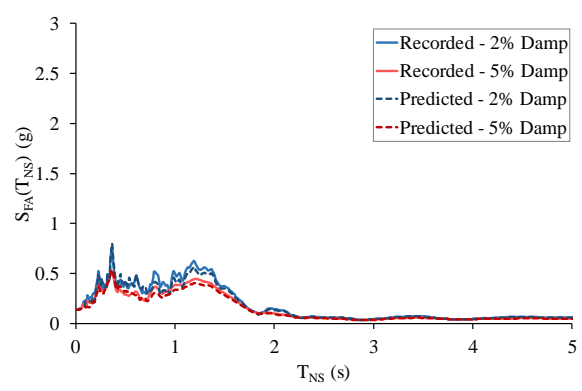

(g) Acceleration FRS - Floor 1 .

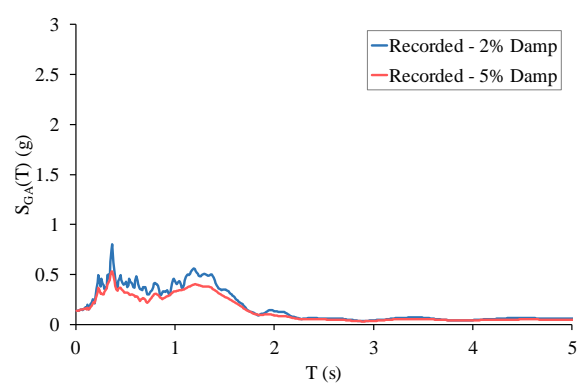

(i) Acceleration GRS - Ground.

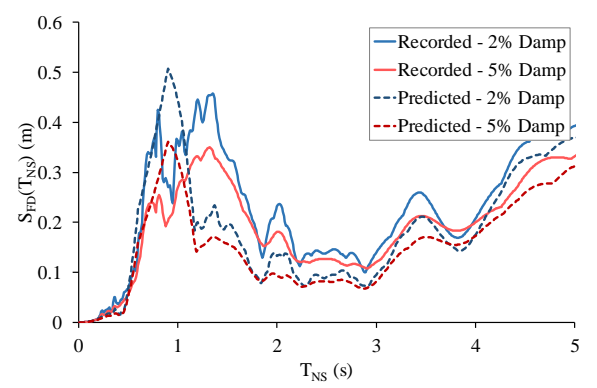

(b) Displacement FRS - Floor 9.

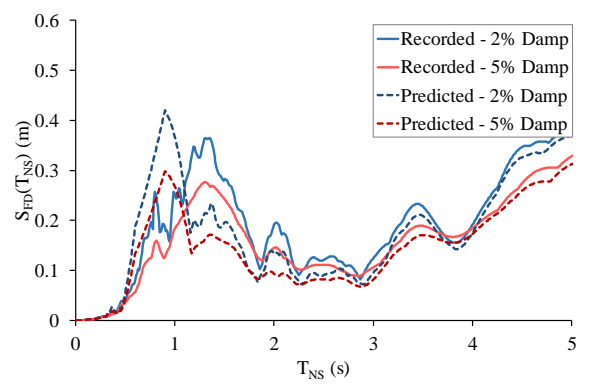

(d) Displacement FRS - Floor 6.

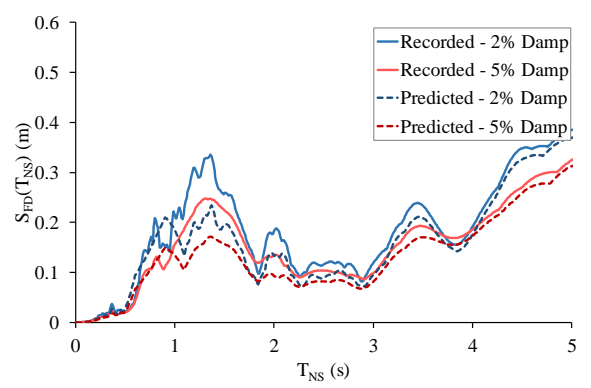

(f) Displacement FRS - Floor 3.

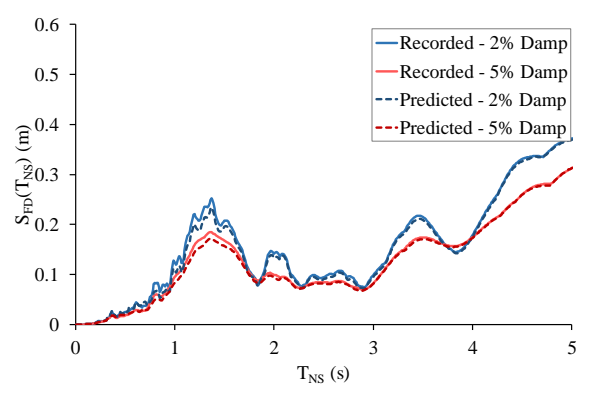

(h) Displacement FRS - Floor 1 .

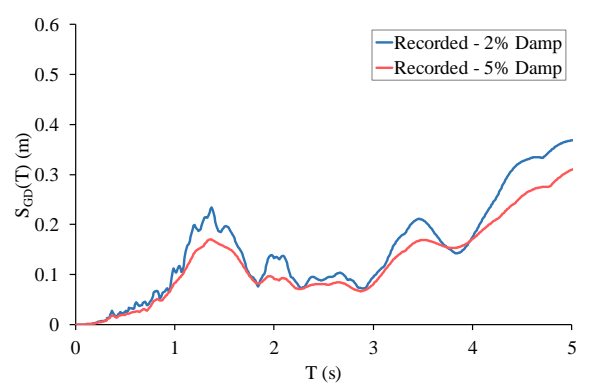

(j) Displacement GRS - Ground.

Figure 8: Recorded and predicted acceleration and displacement floor response spectra (FRS) for the MBIE Stout St building for the Kaikōura 2016 earthquake in the longitudinal direction of floors 1, 3, 6, and 9, at $2 \%$ and 5\% nonstructural component damping. Ground acceleration and displacement response spectra (GRS) are also plotted at $2 \%$ and $5 \%$ nonstructural damping. 


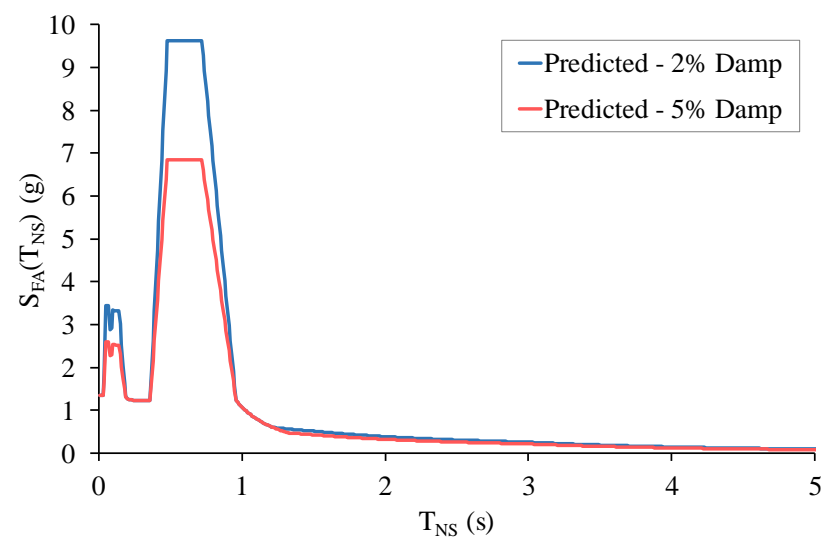

(a) Acceleration FRS.

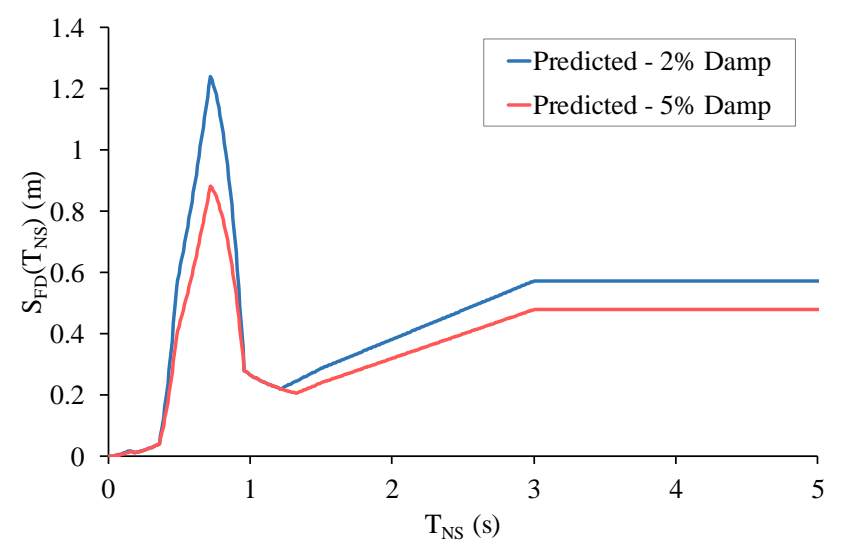

(b) Displacement FRS.

Figure 9: Acceleration and displacement floor response spectra using the proposed method to design level earthquake in UC Physics Building at the roof in the transverse direction at $2 \%$ and $5 \%$ nonstructural damping.

spectra and floor displacement response spectra is observed at all floors at long periods. In the floor displacement response spectra in Figure 8, where $T_{N S}$ is longer than $2 \mathrm{~s}$ (approximately 2.5T ) only minor amplification from the ground response spectrum with increasing floor height can be observed. This amplification is assumed negligible for practical engineering applications. As shown in Figure 8, taking the maximum of the combined modal response and the ground acceleration response spectrum provides sufficiently accurate predictions at these periods.

The peak floor acceleration of the floor acceleration response spectra at floors 3 and 9 in Figure 8 (near $T_{N S}=0$ ) are predicted at lower intensities than the recorded spectra. This may be due to uncertainty in the assessment of the spectral acceleration of each mode of the building used in Equation $1, S_{G A}\left(T_{i}, \xi_{s t r}\right)$. As observed in Figure 7, the recorded ground response spectra have large spectral acceleration differences across small increments of period. Consequently, the scaling of the modal contributions by $S_{G A}\left(T_{i}, \xi_{s t r}\right)$ is sensitive to the exact period value assumed. In practice, however, the floor acceleration response spectrum would be estimated using a code-derived design ground acceleration response spectrum and thus such uncertainties would not be as significant.

In practice, the proposed method will likely be used with a design ground acceleration response spectrum prescribed by a standard. Figure 9 shows the design floor acceleration response spectrum and design displacement response spectrum computed using the design ground acceleration response spectrum for the UC Physics building given in NZS1170.5 [20]. The figure shows the spectra produced for the transverse direction, taking $T_{1}=0.60 \mathrm{~s}$, at $2 \%$ and $5 \%$ nonstructural damping. These spectra show the smoother shape that is computed using design methods. It can be observed in the design floor displacement response spectrum that the ground response spectrum quickly dominates the spectrum for periods longer than approximately $0.8 \mathrm{~s}$. As noted earlier, these design floor response spectra have large variations over small intervals of nonstructural component period. Uncertainty in the nonstructural component period should be considered when using these spectra, as an overly prescriptive period to design to lower spectral ordinates may not be realistic.

\section{Influence of Uncertainty in Fundamental Period Predictions on Floor Spectra Predictions}

Much of the quality of the prediction relies on predicting the fundamental period of the building, $T_{1}$, accurately. As discussed earlier, empirical methods for predicting $T_{1}$ are available in many codes. The fundamental periods of the instrumented buildings were computed using the empirical method in the commentary of NZS1170.5 [20]. These are given in Table 5 alongside the corresponding $T_{1}$ values determined using the frequency response function (FRF) method. It can be observed that the code method over-predicts $T_{1}$ in all except the BNZ CentrePort building. This is contrary to the general trend noted in the commentary [20] that the empirical method would give a shorter fundamental period which thus provide a conservative design spectral acceleration.

To illustrate how the accuracy of the prediction of $T_{1}$ can impact the floor acceleration response spectra produced using the proposed method, floor spectra for the longitudinal direction of the UC Physics building are examined herein. This example was chosen since the fundamental period assessed by the empirical NZS1170.5 method disagreed most with that inferred using the FRF method. The empirical method was used assuming the walls and coupling beams acted as a wall system. The periods of modes 2 and 3 were predicted using the ratios given in Table 2, and are summarised in Table 6.

To compare performance, the proposed method was applied to predict the response in the M6.3 Lyttelton 2011 earthquake at the roof using the $T_{1}$ values from empirical code and FRF methods. The 5\%-damped floor acceleration response spectra predicted are shown in Figure 10. The DAF is only wide enough to capture the spectral acceleration near the observed fundamental period (between $0.3 \mathrm{~s}$ to $0.7 \mathrm{~s}$ ) for the floor acceleration response spectrum prediction where $T_{1}$ was inferred by FRF, failing to do so for the spectrum predicted using $T_{1}$ from the empirical method. In both floor acceleration response spectrum predictions the peak spectral acceleration of the fundamental mode is lower than the observed response. This is likely due to the ground level spectral ordinates that correspond to the fundamental periods inferred

Table 6: Periods of vibration used to determine the floor acceleration response spectra in the UC Physics building using the frequency response function (FRF), the empirical equation given for $T_{1}$ in the commentary NZS1170.5, and eigenvalue analysis.

\begin{tabular}{cccc}
\hline Method & $T_{1}(\mathbf{s})$ & $T_{2}(\mathbf{s})$ & $T_{3}(\mathbf{s})$ \\
\hline FRF & 0.46 & 0.15 & 0.08 \\
NZS1170.5 & 0.65 & 0.13 & 0.08 \\
Eigenvalue & 0.28 & 0.10 & 0.08 \\
\hline
\end{tabular}


using these methods.

An eigenvalue analysis was undertaken as an alternate means to assess the modal properties required by the proposed method. This was computed using a 2D frame model of the longitudinal direction of the UC Physics building adapted from McHattie [24]. The cracked flexural stiffnesses of the walls and coupling beams were assumed to be $50 \%$ of the uncracked state, corresponding to the effective stiffness properties recommended at serviceability limit state intensity with the assumed ductility $\mu=3$ for walls and coupling beams given in NZS3101:2006 [27]. The periods of vibration found using eigenvalue analysis are shown in Table 6. Figure 10 shows the performance of the proposed floor spectrum using the periods of vibration found using the FRF and eigenvalue analysis methods. Here, as the eigenvalue analysis under-predicted $T_{1}$, the assessed peak again falls outside of the fundamental mode amplification range observed from the record.

Potentially more accurate predictions of $T_{1}$ can be achieved in practice through instrumentation of a building where the structural system has been constructed, such as in design for the retrofit of components within an existing structure. A low-cost accelerometer could be mounted at the roof level to record ambient building motion caused by strong wind or low intensity earthquakes. This could be processed to determine the fundamen-

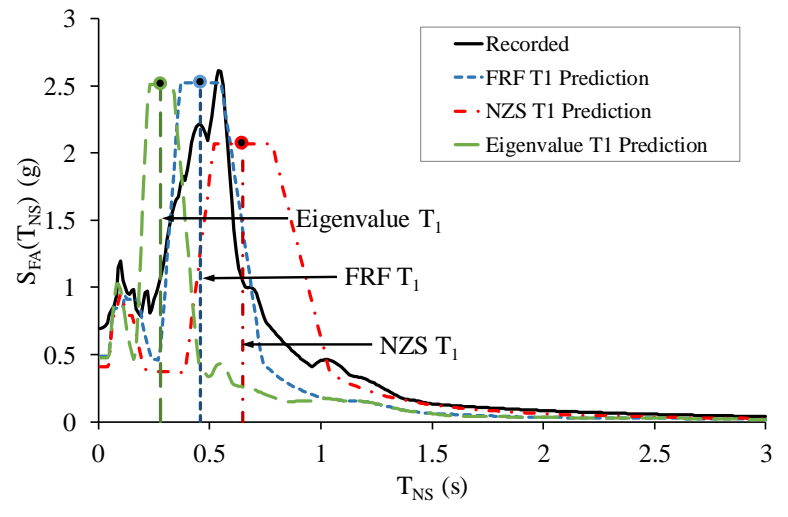

Figure 10: Floor acceleration response spectra for the UC Physics building for the Lyttelton 2011 earthquake record in the longitudinal direction at the roof. Predicted acceleration spectra are overlaid made using the proposed method using the fundamental periods inferred by the frequency response function (FRF) and the method proposed in the New Zealand standard NZS1170.5. Spectra are given at 5\% nonstructural damping. tal period for use in the proposed method, potentially improving the accuracy of the floor acceleration response spectra calculated. The prediction may be affected by additional sources of stiffness at low intensities which may be different at the design response for design hazard intensities. This would likely result in a shorter fundamental period predicted which would be conservative when used with a design ground acceleration response spectrum. This discrepancy may not make significant difference to a predicted floor acceleration response spectrum due to the broad nature of the amplification region of the DAF.

\section{Comparison of the Proposed and Code Floor Spectra Meth- ods}

Figure 11 compares the performance of the proposed method against the international code methods Eurocode 8 [21], NZS1170.5 [20], and the ASCE 7-16 alternate method [2]. This figure shows the floor acceleration response spectra and floor displacement response spectra computed for the UC Physics building M6.3 Lyttelton 2011 earthquake record in the transverse direction at the roof at $2 \%$ and $5 \%$ nonstructural damping. The proposed method can predict the high amplification of the fundamental mode where the code methods do not. The higher mode ranges are captured where Eurocode 8 neglects them. The peak floor acceleration, at $S_{F A, i, j}\left(T_{N S}=0, \xi_{N S}\right)$, is more accurately represented than the over-conservative NZS1170.5 approach. The less conservative design acceleration requirements will result in lower costs for rigid components. This is especially relevant for heavy plant components for which design in accordance with current requirements can be prohibitively expensive. Beyond the $T_{1}$ amplification peak, between $0.8 \mathrm{~s}$ and $1.5 \mathrm{~s}$, the proposed method again follows closer to the recorded spectra than the code approaches which are conservative for that period range. At longer periods in the displacement spectra the code predictions do not follow the physical behaviour, while the proposed method is able to provide more reasonable estimates. The proposed method is further able to capture increased dynamic amplification at lower values of nonstructural damping whereas the international code methods cannot.

\section{Application of Proposed Method to Inelastic Building Re- sponses}

To gauge the applicability of this method to inelastically responding buildings, the response of the BNZ CentrePort building in the Kaikōura 2016 earthquake was examined. As can be seen in Figure 5(h), the Kaikōura 2016 event was near the ULS design intensity level at the spectral acceleration corresponding to the transverse elastic fundamental period. This resulted in

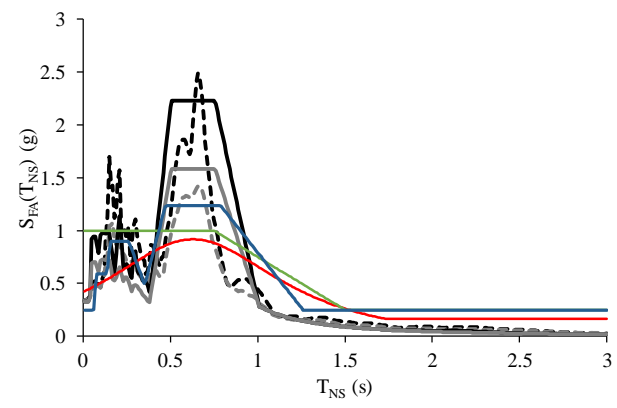

(a) Acceleration FRS.

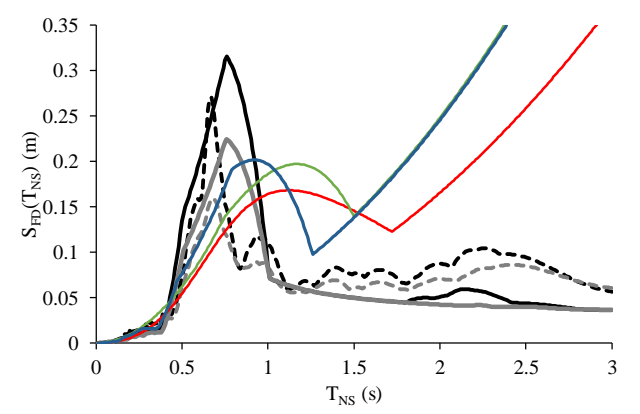

(b) Displacement FRS.

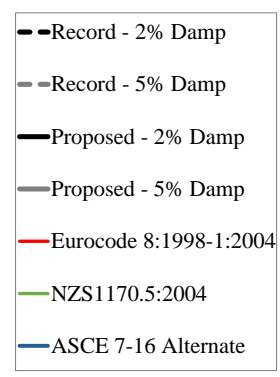

Figure 11: Acceleration and displacement floor response spectra for the UC Physics building Lyttelton 2011 earthquake record in the transverse direction at the roof at $2 \%$ and $5 \%$ nonstructural damping. Predictions at these damping values are shown for the proposed method, Eurocode 8, NZS1170.5, and the ASCE 7-16 alternate method, the latter three not varying with nonstructural damping. 


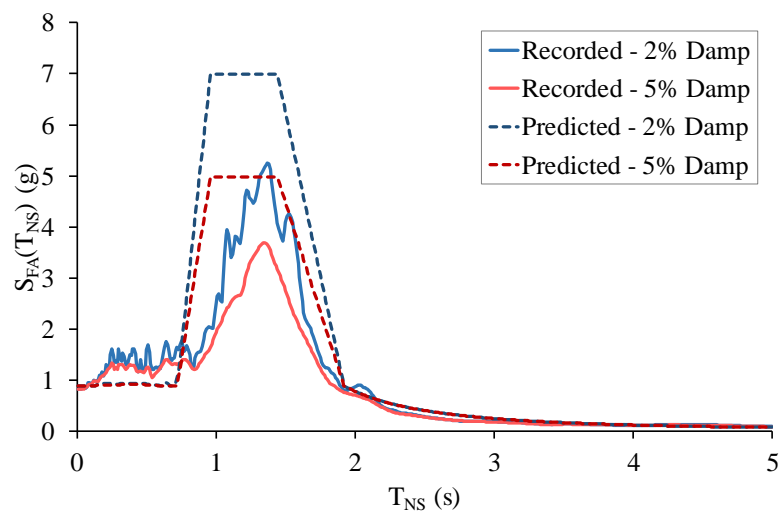

(a) Acceleration FRS.

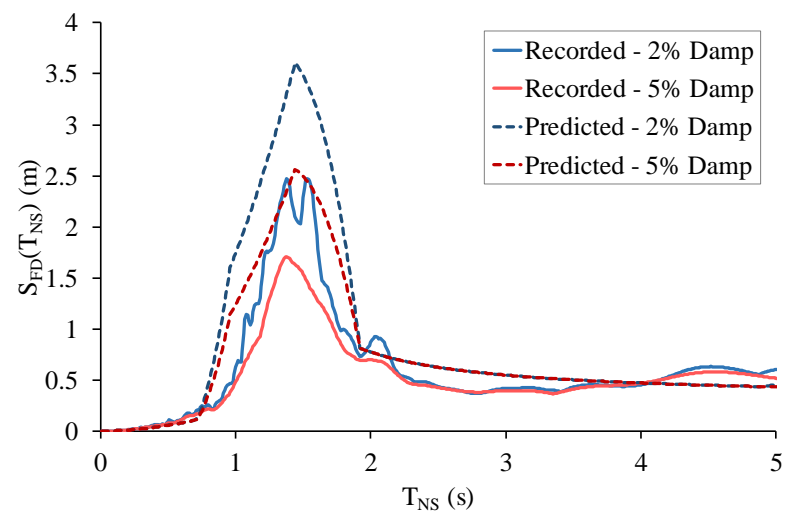

(b) Displacement FRS.

Figure 12: Acceleration and displacement floor response spectra (FRS) for the BNZ CentrePort building for the Kaikoura 2016 earthquake in the transverse direction at floor 5 at $2 \%$ and $5 \%$ nonstructural damping.

the structural system responding inelastically [25]. Figure 12 shows the predicted and recorded floor acceleration response spectrum and floor displacement response spectrum for in the transverse direction at floor 5. This uses a fundamental period of $1.20 \mathrm{~s}$, inferred from the FRF of the M6.6 Grassmere 2013 earthquake motion records. The fundamental period appears to have elongated to approximately $1.40 \mathrm{~s}$, widening the corresponding amplification peak. The recorded peak spectral acceleration and peak spectral displacement are lower than that predicted by the elastic prediction method, as suggested by methods proposed in literature $[4 ; 7 ; 14]$. Future research aims to incorporate a means of accounting for inelastic building behaviour in the method proposed here.

\section{Quantifying the Error in Predicted Floor Spectra}

To assess the overall performance of the proposed method, the estimated and recorded floor acceleration response spectra at the roof level of each building are compared to the corresponding code predictions for the events listed in Table 4 . Both orthogonal directions are examined at $2 \%$ and $5 \%$ nonstructural component damping. The predictions used the fundamental periods inferred using FRF, as summarised in Table 4. To measure the error between the recorded and predicted spectra the mean percentage error (MPE) was calculated using Equation 11:

$$
\operatorname{MPE}(\%)=\frac{100 \%}{n_{T_{N S}}} \sum_{n=1}^{n_{T_{N S}}} \frac{\left|S_{F A, \text { Predict }, n}-S_{F A, \text { Record }, n}\right|}{S_{F A, \text { Record }, n}}
$$

where $n_{T_{N S}}$ is the number of $T_{N S}$ points in the spectrum.

After approximately $T_{N S}=1.5 \mathrm{~s}$ significant divergence between all of the code approach floor acceleration response spectra and the recorded spectrum is expected. Where spectra are computed with periods longer than $T_{N S}=2 \mathrm{~s}$, the mean percentage errors measured are dominated by the long period ordinates. This domination is not clearly visible in plots with linear axes as both recorded and predicted spectra have low spectral acceleration at long periods. Instead, this divergence can be observed in the floor displacement response spectra in Figure 11(b). To enable reasonable comparison between the methods, therefore, the floor acceleration response spectra produced for error measurement were created from $T_{N S}=0.01 \mathrm{~s}$ to $2 \mathrm{~s}$, with an interval of $0.01 \mathrm{~s}$. The results of this error measurement method are presented in Figures 13 and 14 for 2\% and 5\% nonstructural damped spectra, respectively.

It can be observed in both Figures 13 and 14 that the proposed method generally performs better than the code approaches in both orthogonal directions for the UC Physics building and the Avalon GNS buildings. The proposed method was, on average, $28 \%$ lower than the best performing international code method from these cases, Eurocode 8. The modifications made to the ASCE 7-16 method which comprise the proposed method, the modified DAF shape and modified maximum DAF, resulted in reliably improved acceleration response spectrum predictions. This was evidenced by the significantly lower error measured for spectra predicted using the proposed method compared to the ASCE 7-16 method.

Previous literature has reported the Eurocode 8 method may perform poorly as it neglects amplification of demands at higher modes of the building [7]. This is observed in the high error measured for the Eurocode 8 method compared with the proposed method for most buildings in Figures 13 and 14. There is the notable exception of the BNZ building, for which the error computed was significantly lower than the other methods, particularly in the longitudinal direction. This case is investigated in Figure 15(a), where the code method predictions, the proposed method prediction, and recorded floor acceleration response spectra are shown for the Kaikoura earthquake motion recorded in the longitudinal direction of the BNZ building, at $2 \%$ and $5 \%$ nonstructural damping. Here no strong higher mode responses are recorded, which Eurocode 8 assumes. The shape of the Eurocode 8 spectrum is also seen to better capture the changes in the floor acceleration response spectrum due to the structure behaving inelastically, although the spectral accelerations are far too low. This includes better following the wide fundamental mode amplification of spectral accelerations due the elongation of the fundamental period, and the lower spectral accelerations observed than predicted by the proposed and ASCE 7-16 methods which use elastic modal properties. The limited benefit of using the Eurocode 8 prediction method, however, was observed in the poorer measured performance for predicting the response of the other buildings. This is particularly relevant where higher mode responses are more dominant, which is the case for the longitudinal directions of the UC Physics building and the MBIE Stout St building. This can be seen by comparing the Eurocode 8 predictions and recorded floor acceleration response spectra for these cases in Figures 11(a) and 16(a).

The error measured for the MBIE Stout St building is interesting as all methods performed almost equally as well, as seen in Figures 13 and 14. Figure 16(a) shows the predictions and recorded floor acceleration response spectra for the Kaikōura earthquake motion recorded in the longitudinal direction at $2 \%$ 


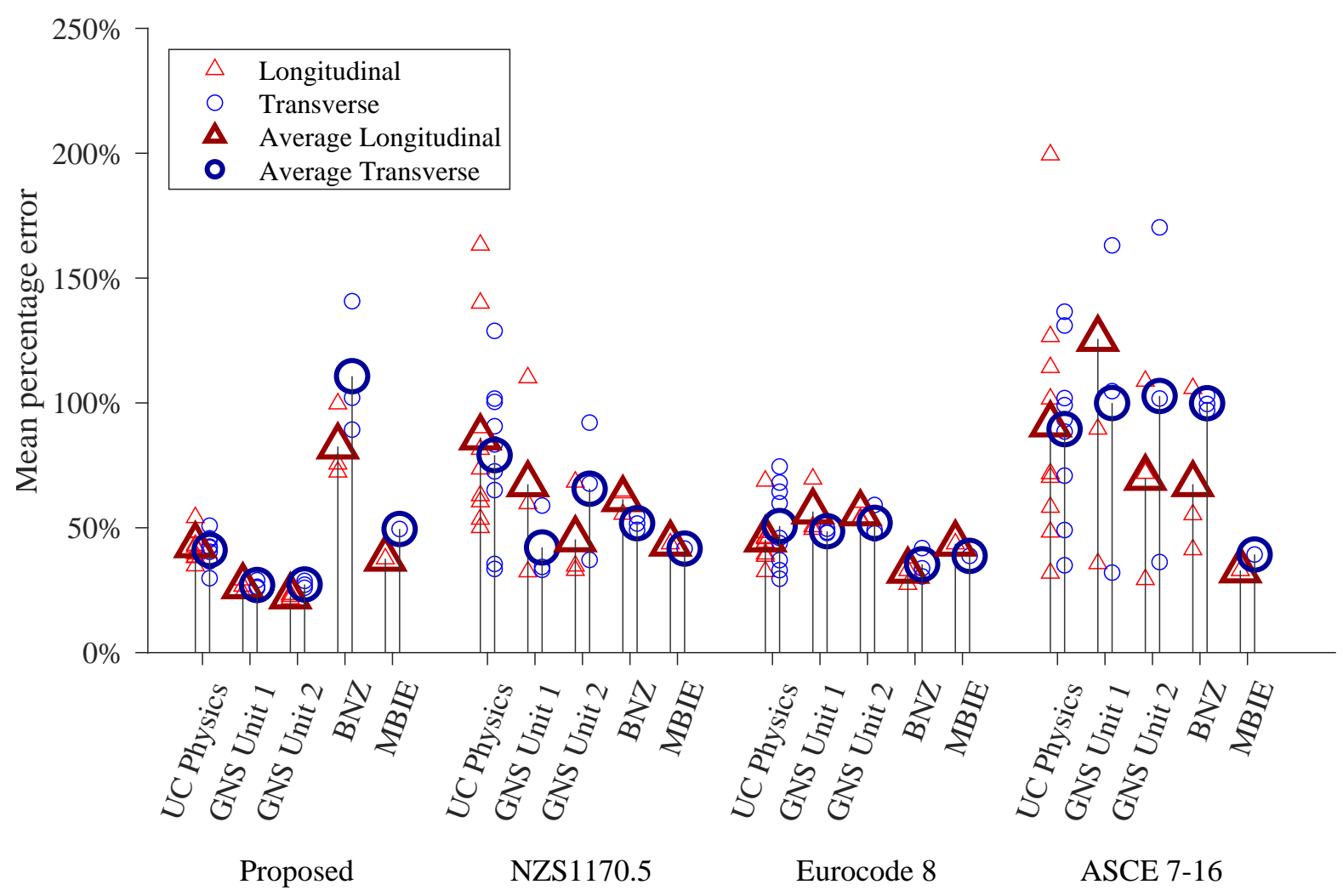

Figure 13: Mean percentage error each event for the case study buildings at the roof level in each orthogonal direction at $2 \%$ nonstructural damping, using the $T_{1}$ determined in each event using FRF.

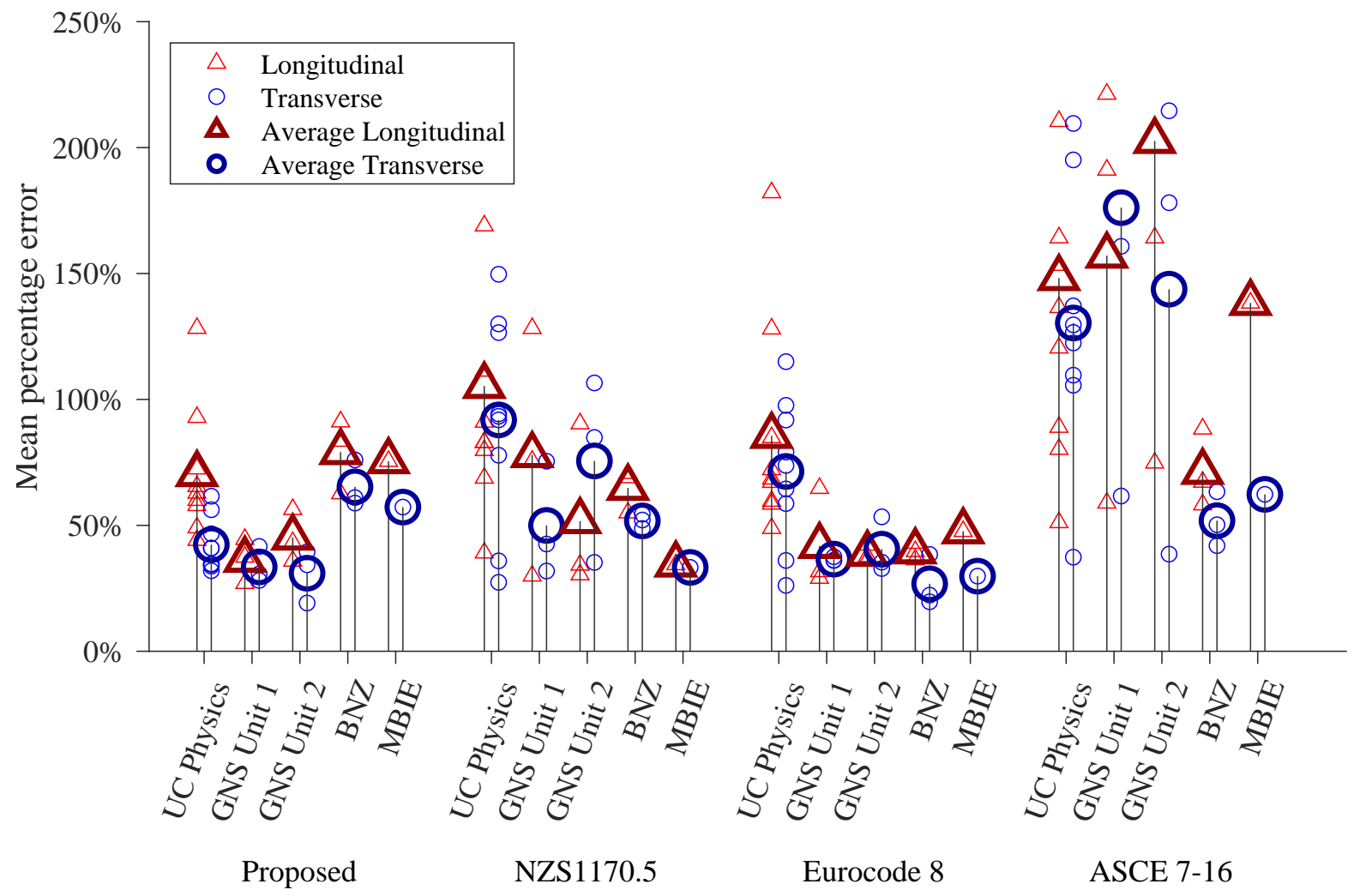

Figure 14: Mean percentage error each event for the case study buildings at the roof level in each orthogonal direction at 5\% nonstructural damping, using the $T_{1}$ determined in each event using FRF. 
and 5\% nonstructural damping. This illustrates that the modal methods make good approximations to the fundamental mode amplification peak, though fail to assess the correct intensity of the higher mode responses. The proposed method also reduces too quickly after the fundamental mode plateau in this case. The Eurocode 8 and NZS1170.5 methods are off by approximately the same amount for all spectral ordinates, though follow the general shape and thereby have similar error measurements to the modal approaches. These differences appear to have averaged to produce similar error measurements. This suggests a possible issue with how the error is quantified, as Figure 16 (a) makes the proposed and ASCE methods appear far more reflective of the recorded spectra than the Eurocode 8 and NZS1170.5 approaches.

\section{Measured Impact of using Simplified Estimates of $T_{1}$}

As explained earlier, one means of maintaining a simplified floor response spectrum approach could be to use simplified estimates of $T_{1}$. To assess how this may impact accuracy, the various prediction methods were applied again using the simplified period expressions from the commentary of NZS1170.5, and error values recomputed. The results are presented in Figures 17 and 18 for $2 \%$ and $5 \%$ nonstructural damped spectra, respectively. Although the NZS1170.5 floor acceleration response spectrum method does not rely on $T_{1}$, and thus the error does not change, it is presented here for comparison with the other approaches.

The direct correlation of the quality of the assessment of $T_{1}$ to the floor acceleration response spectrum produced by these simplified methods can be observed by comparing error measured in the spectra predicted using $T_{1}$ inferred from FRF, Figures 13 and 14 , with those predicted using $T_{1}$ predicted using the empirical method, Figures 17 and 18. It is most clear by comparing for the longitudinal and transverse directions of the UC Physics buildings. In the longitudinal direction, where the empirical code prediction of $T_{1}$ is far from the average FRF $T_{1}, 0.65 \mathrm{~s}$ to $0.42 \mathrm{~s}$ respectively, the proposed method error averaged across the events increased dramatically. In contrast, the empirical code assessment of $T_{1}$ is far closer to the average FRF $T_{1}$ in the transverse direction, $0.65 \mathrm{~s}$ to $0.60 \mathrm{~s}$ respectively, which resulted in a relatively minor increase in error. This shows for small uncertainty in assessing $T_{1}$, the width of the DAF allows for variation in the true narrow observed amplification peak recorded in these events. This is seen similarly in the Avalon GNS buildings, where the broad amplification peaks capture this uncertainty and only a minor increase in error is observed. If wider peaks are used greater conservatism is given to address this uncertainty. This may not, however, reduce the error as the then-overpredicted range would dominate the measurement. This illustrates the balancing of conservation and accuracy that this simplified approach is attempting to find, and which this error measurement method penalises the former.

To visualise how these predictions change with different $T_{1}$ values, Figures 15(b) and 16(b) provide predicted and recorded floor acceleration response spectra using the periods inferred using the empirical code method for the same cases as Figures 15(a) and 16(b).

\section{CONCLUSION}

A practice-oriented method for the prediction of elastic floor acceleration response spectra and floor displacement response spectra in buildings has been proposed. The method aims to improve upon previous methods by accounting for many phys-

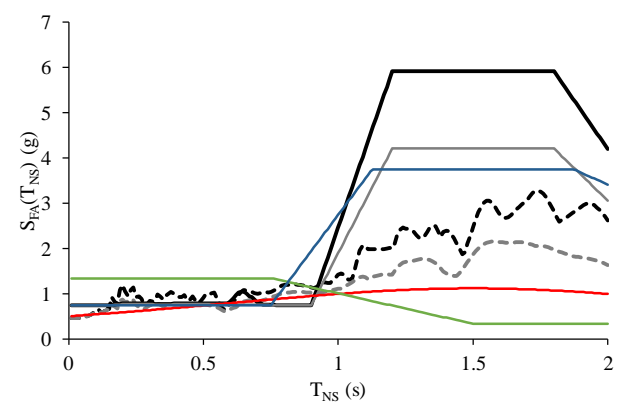

(a) FRS with $T_{1}$ inferred using FRF.

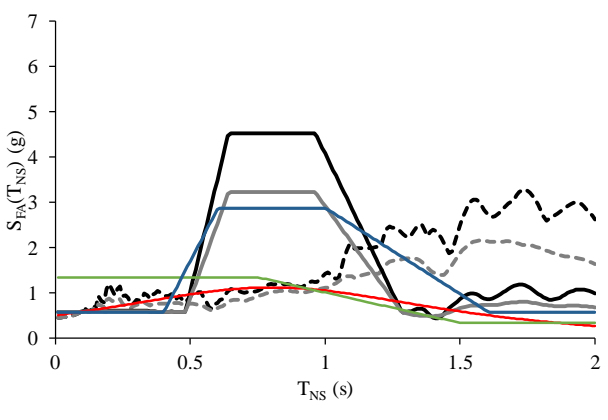

(b) FRS with $T_{1}$ using NZS1170.5 empirical method.

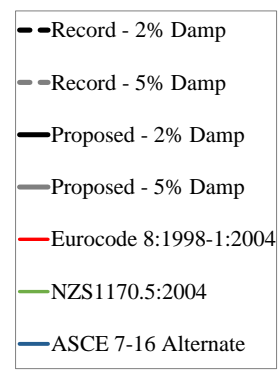

Figure 15: Performance of code and proposed methods using fundamental periods inferred using frequency response functions (FRF) and the NZS1170.5 empirical method for estimating roof level acceleration floor response spectra (FRS) in the longitudinal direction of the BNZ CentrePort building for the Kaikōura earthquake at $2 \%$ and $5 \%$ damping.

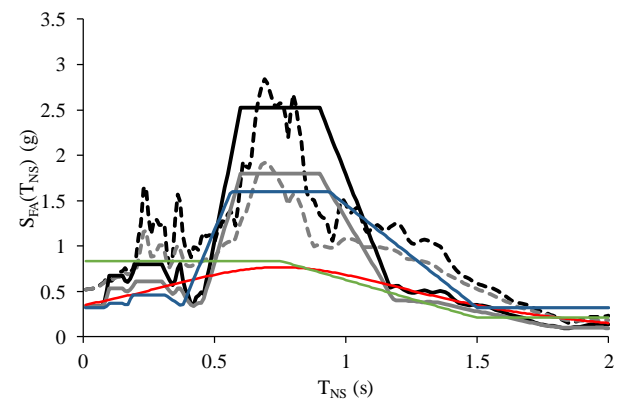

(a) FRS with $T_{1}$ inferred using FRF.

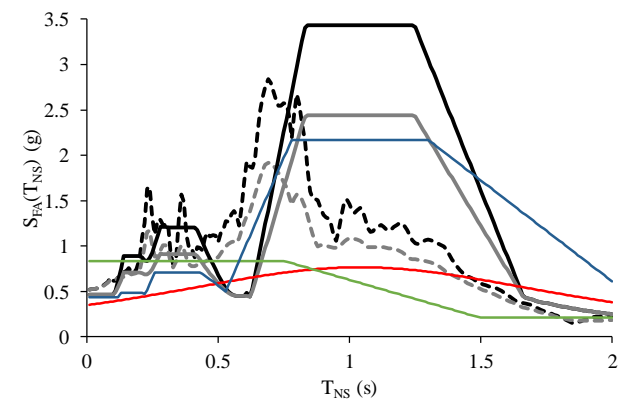

(b) FRS with $T_{1}$ using NZS1170.5 empirical method.

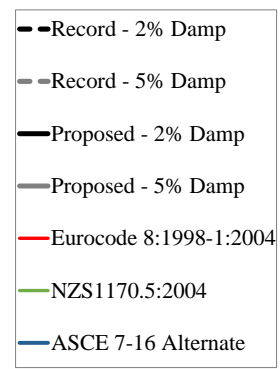

-ASCE 7-16 Alternate

Figure 16: Performance of code and proposed methods using fundamental periods inferred using frequency response functions (FRF) and the NZS1170.5 empirical method for estimating roof level acceleration floor response spectra (FRS) in the longitudinal direction of the MBIE Stout St building for the Kaikoura earthquake at $2 \%$ and $5 \%$ damping. 


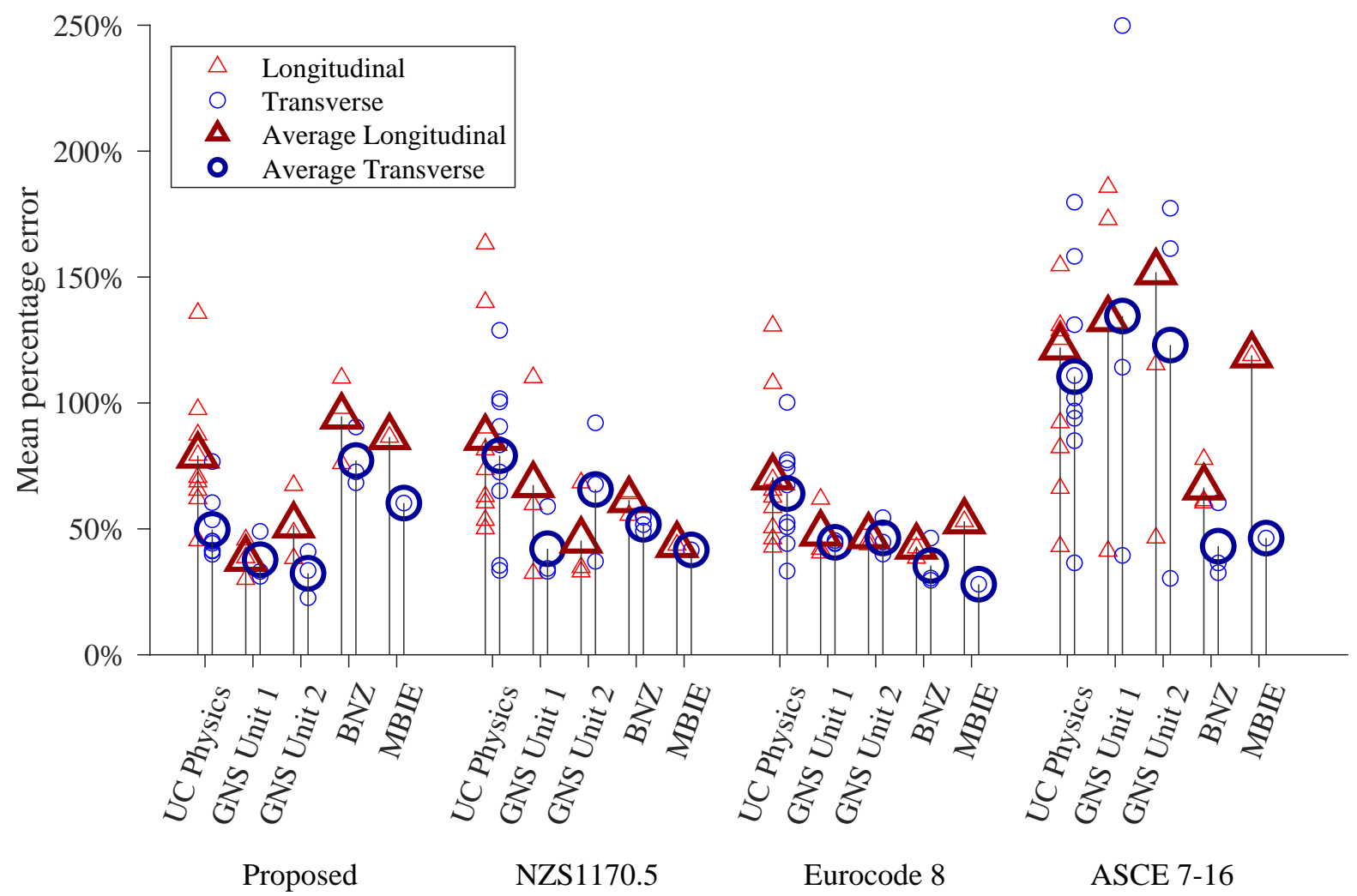

Figure 17: Mean percentage error each event for the case study buildings at the roof level in each orthogonal direction at 2\% nonstructural damping, using the $T_{1}$ determined in each event using NZS1170.5 commentary expression for building period.

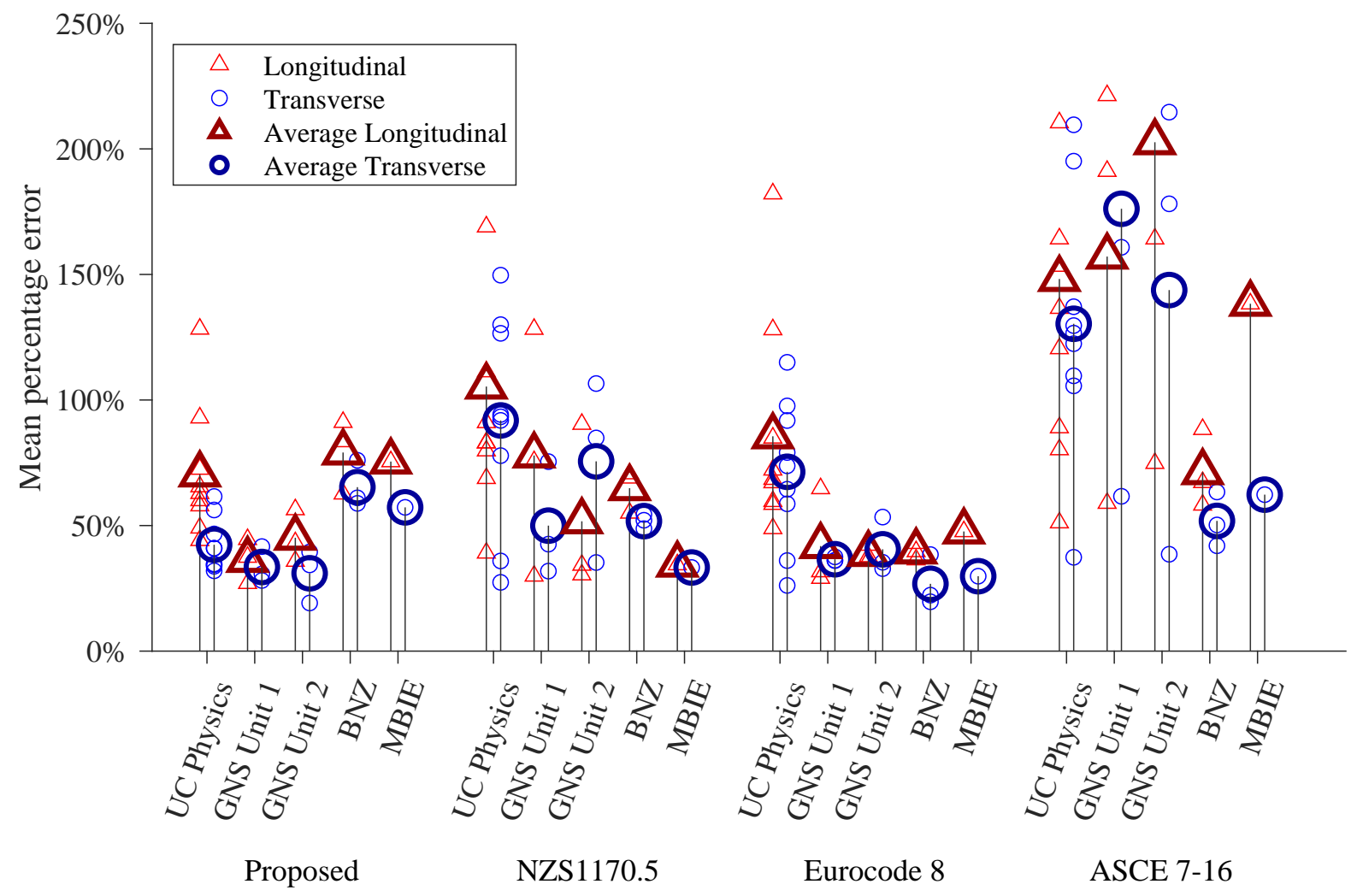

Figure 18: Mean percentage error each event for the case study buildings at the roof level in each orthogonal direction at 5\% nonstructural damping, using the $T_{1}$ determined in each event using NZS1170.5 commentary expression for building period. 
ical factors that influence floor acceleration response spectra while aiming for a method that is easy to use. This was built on previous proposals, where a dynamic amplification factor (DAF) models the dynamic amplification due to resonance between the mounted component and the structural modes at varying levels of damping of the nonstructural component. The shape of the DAF proposed was modified from the simple shape proposed in ASCE 7-16, adopting a decay at long component periods to explicitly consider the derivation of floor displacement response spectra from floor acceleration response spectra. Rigid body motion was accounted for by taking final floor acceleration response spectrum prediction as the maximum of both the combined contribution of the modes to the floor acceleration response spectrum and the ground acceleration response spectrum.

A novel approach was used to assess the accuracy of the proposed method by comparing recorded floor acceleration spectra from five GeoNet Structural Array instrumented buildings to predictions computed using the proposed method. This was compared with the predictions made using the NZS1170.5, Eurocode 8, and ASCE 7-16 code methods. Performance was measured by computing the mean percentage errors between the predictions and records, computed for roof-level floor acceleration response spectra damped at $2 \%$ and $5 \%$. For the spectra produced from records where the buildings responded elastically in the 12 investigated earthquakes, the error measured was on average $28 \%$ lower for the predictions made by the proposed method compared to the best performing international code method, Eurocode 8. The observation that the Eurocode 8 method performed well may be a function of how the error is quantified, as this in contrast to other studies in the literature and likely reflects the low participation of higher modes in the selected case study buildings.

The accuracy of a floor acceleration response spectrum predicted using the proposed method is heavily dependent on the accuracy of the predicted fundamental period of vibration of the building. Simplified empirical expressions for $T_{1}$ from the commentary of NZS1170.5 were trialled and found to be unreliable. It is suggested that modal characteristics of the structure are assessed through eigenvalue analysis where possible.

The proposed method currently has been formulated only for the case in which buildings respond elastically and so may be suitable for serviceability limit state (SLS) intensity levels. Further work is required to extend the method to intensities where buildings and components respond non-linearly, like the ultimate limit state (ULS) intensity. To account for this and further uncertainties yet to be fully investigated, broad period ratios used to define DAF are recommended.

There is an expectation that the nonstructural components, too, have some ductility capacity. Further research may show that the narrow, high spectral acceleration peaks from the modes of the building observed in elastic spectra do not present significant problems provided that components possess some ductility and thus expressions for inelastic floor spectra should also be developed. However, it is also expected that these narrow peaks can be avoided by bracing a nonstructural element to reduce its fundamental period away from the periods of the building. Information is also limited on the values expected for the damping of specific types of nonstructural components. Since floor acceleration response spectra were observed to amplify significantly with decreasing damping values for nonstructural components, this topic should also be a subject of future research.

\section{ACKNOWLEDGEMENTS}

The use of the GeoNet structural array enabled the verification and refinement of the method presented in this paper. Thanks are given to GeoNet, the tenants and the owners of these buildings for the foresight in instrumenting these structures to provide such an excellent engineering resource which proved invaluable in this research.

This project was (partially) supported by QuakeCoRE, a New Zealand Tertiary Education Commission-funded Centre.This is QuakeCoRE publication number 0470.

\section{REFERENCES}

1 Kehoe BE and Hachem M (2003). "Procedures for Estimating Floor Accelerations". ATC-29-2 Seminar on Seismic Design, Performance, and Retrofit of Nonstructural Components in Critical Facilities, Applied Technology Council, Redwood City, California, pp. 361-374.

2 American Society of Civil Engineers (2017). ASCE/SEI 7-16: Minimum design loads and associated criteria for buildings and other structures. American Society of Civil Engineers, Reston, Virginia, 834 pp.

3 Calvi PM and Sullivan TJ (2014). "Estimating floor spectra in multiple degree of freedom systems". Earthquakes and Structures, 7(1): 17-38. https://doi.org/10.12989/eas.2014.7. 1.017

4 Welch D and Sullivan T (2017). "Illustrating a new possibility for the estimation of floor spectra in nonlinear multidegree of freedom systems". 16th World Conference on Earthquake Engineering, 212, Santiago, Chile, p. pp 12.

5 GeoNet (2019). "Structural Array Data". https://www.geonet. org.nz/data/types/structural \{_\}arrays

6 Dhakal RP, Pourali A, Tasligedik AS, Yeow T, Baird A, MacRae G, Pampanin S and Palermo A (2016). "Seismic performance of non-structural components and contents in buildings: an overview of NZ research". Earthquake Engineering and Engineering Vibration, 15(1): 1-17. https://doi.org/0.1007/s11803-016-0301-9

7 Sullivan TJ, Calvi PM and Nascimbene R (2013). "Towards improved floor spectra estimates for seismic design". Earthquakes and Structures, 4(1): 109-132. https://doi.org/10. 12989/eas.2013.4.1.109

8 Filiatrault A and Sullivan T (2014). "Performance-based seismic design of nonstructural building components: The next frontier of earthquake engineering". Earthquake Engineering and Engineering Vibration, 13(S1): 17-46. https: //doi.org/10.1007/s11803-014-0238-9

9 Baird A and Ferner H (2017). "Damage to non-structural elements in the 2016 Kaikōura earthquake". Bulletin of the New Zealand Society for Earthquake Engineering, 50(2): 187-193. https://doi.org/10.5459/bnzsee.50.2.187-193

10 Ferner H, Wemyss M, Baird A, Beer A and Hunter D (2014). "Seismic performance of non-structural elements within buildings". 2014 NZSEE Conference, Auckland, New Zealand, pp. 1-9.

11 Applied Technology Council (2018). Recommendations for improved seismic performance of nonstructural components. Tech. rep., Applied Technology Council, Redwood City. https://doi.org/10.6028/NIST.GCR.18-917-43

12 Anajafi H and Medina RA (2018). "Evaluation of ASCE 7 equations for designing acceleration-sensitive nonstructural components using data from instrumented buildings". Earthquake Engineering \& Structural Dynamics, 47(4): 10751094. https://doi.org/10.1002/eqe.3006

13 Flores FX, Lopez-Garcia D and Charney F (2015). "Acceler- 
ation demands on nonstructural components in special steel moment frames". XI Chilean Conference on Seismology and Earthquake Engineering ACHISINA, 212, Pontificia Universidad Catolica de Chile. Santiago, Chile., p. pp 12.

14 Vukobratović V and Fajfar P (2017). "Code-oriented floor acceleration spectra for building structures". Bulletin of Earthquake Engineering, 15(7): 3013-3026. https://doi.org/10. 1007/s10518-016-0076-4

15 Calvi PM (2014). "Relative Displacement Floor Spectra for Seismic Design of Non Structural Elements”. Journal of Earthquake Engineering, 18(7): 1037-1059. https://doi.org/ 10.1080/13632469.2014.923795

16 Biggs J (1971). "Seismic response spectra for equipment design in nuclear power plants". First International Conference on "Structural Mechanics in Reactor Technology", Berlin, Germany, pp. 329-343.

17 Kehoe BE (2014). "Defining rigid vs. flexible nonstructural components". Tenth U.S. National Conference on Earthquake Engineering, Anchorage, AK, USA., pp. 1-11.

18 Pozzi M and Der Kiureghian A (2012). "Response spectrum analysis for floor acceleration". 15th World Conference on Earthquake Engineering, Lisbon, Portugal, pp. 29906 29915.

19 Watkins D, Chui L, Hutchinson T and Hoehler M (2010). Survey and Characterisation of Floor and Wall Mounted Mechanical and Electrical Equipment in Buildings. Report No. SSRP-2009/11. Tech. rep., Department of Structural Engineering, University of California, San Diego.

20 Standards New Zealand (2016). NZS 1170.5:2004: Structural design actions, Part 5: Earthquake actions - New
Zealand. Standards New Zealand, Wellington, New Zealand, $88 \mathrm{pp}$.

21 European Committee for Standardization (2004). Eurocode 8: Design of structures for earthquake resistance - Part 1: General rules, seismic actions and rules for buildings. European Committee for Standardization, Brussels, Belgium, 229 pp.

22 Petrone C, Magliulo G and Manfredi G (2016). "Floor response spectra in RC frame structures designed according to Eurocode 8". Bulletin of Earthquake Engineering, 14(3): 747-767. https://doi.org/10.1007/s10518-015-9846-7

23 Miranda E and Taghavi S (2005). "Approximate Floor Acceleration Demands in Multistory Buildings. I: Formulation". Journal of Structural Engineering, 131(2): 203-211. https: //doi.org/10.1061/(ASCE)0733-9445(2005)131:2(203)

24 McHattie S (2013). Seismic Response of the UC Physics Building in the Canterbury Earthquakes. Master of engineering thesis, University of Canterbury.

25 Chandramohan R, Ma Q, Wotherspoon LM, Bradley BA, Nayyerloo M, Uma SR and Stephens MT (2017). "Response of instrumented buildings under the 2016 Kaikoura earthquake". Bulletin of the New Zealand Society for Earthquake Engineering, 50(2): 237-252. https://doi.org/10.5459/ bnzsee.50.2.237-252

26 Standards New Zealand (2002). AS/NZS 1170.0:2002: Structural design actions, Part 0: General principles. Standards New Zealand, Wellington, New Zealand, 42 pp.

27 Standards New Zealand (2006). NZS 3101:2006: Concrete Structures Standard. Standards New Zealand, Wellington, New Zealand, 756 pp. 
Appendix to

\title{
A PRACTICE-ORIENTED METHOD FOR ESTIMATING ELASTIC FLOOR RESPONSE SPECTRA
}

\author{
Kieran Haymes, Timothy J. Sullivan and Reagan Chandramohan
}

\begin{abstract}
OVERVIEW
This document contains additional tables to assist in enabling the use of the elastic floor response spectrum method proposed in the main work. Tables A1, A2, and A3 provide mode shapes at each floor level for buildings between 1 and 20 storeys tall for modes 1, 2 and 3, respectively. Table A4 provides the participation factors that correspond to these mode shapes.

The values were produced using the method outlined in Miranda and Taghavi [23]. These were produced using the value given
\end{abstract}

in Miranda and Taghavi [23] for the dimensionless variable $\alpha_{0}$ of 3.125, corresponding to a dual shear wall and moment resisting frame lateral force resisting system. For this, interstorey heights, seismic mass lumped at floor levels, and lateral stiffness are assumed to be constant throughout the building's height. The participation factors provided in Table A4 were calculated using Equation 10 in the main work, where the mode shapes are taken as discrete points at the floor levels rather than using the continuous integration method used in Miranda and Taghavi [23]. 


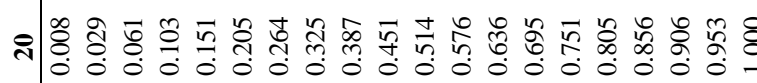

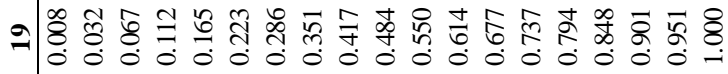

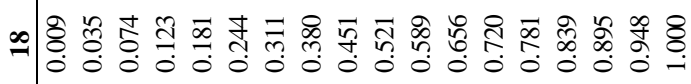

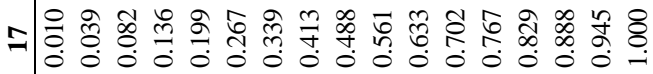

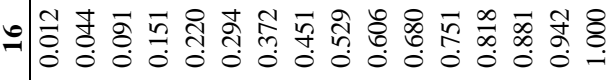

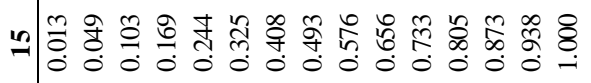

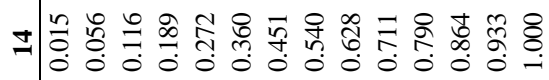

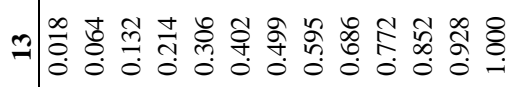

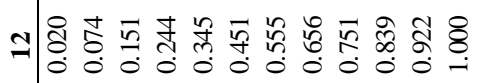

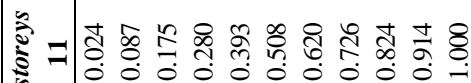

-

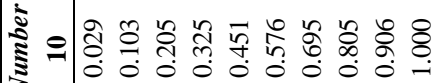

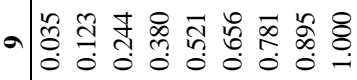

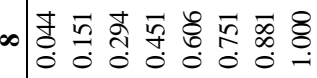

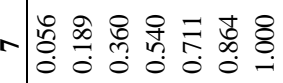

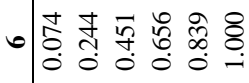

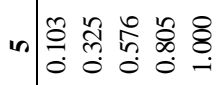

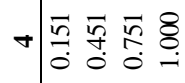

啨总总

川 皇㝵

$-\frac{8}{-8}$
|

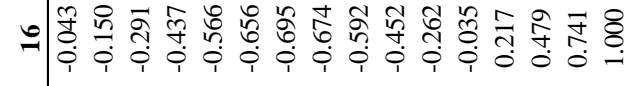

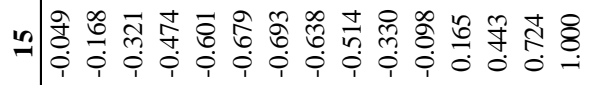

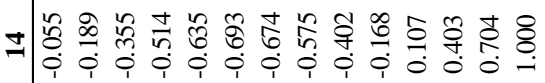

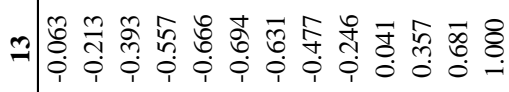

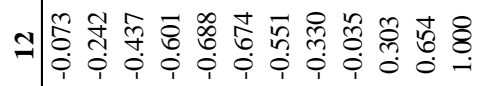

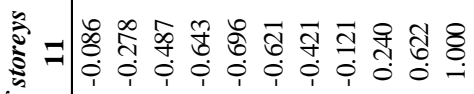

-

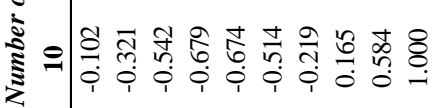

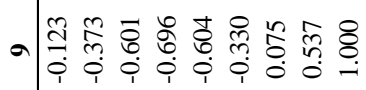

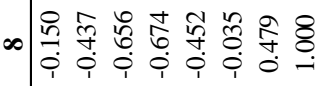

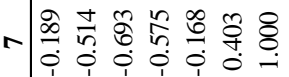

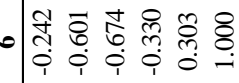

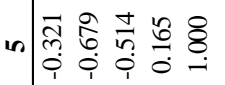

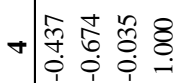

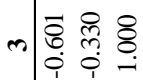

州喜

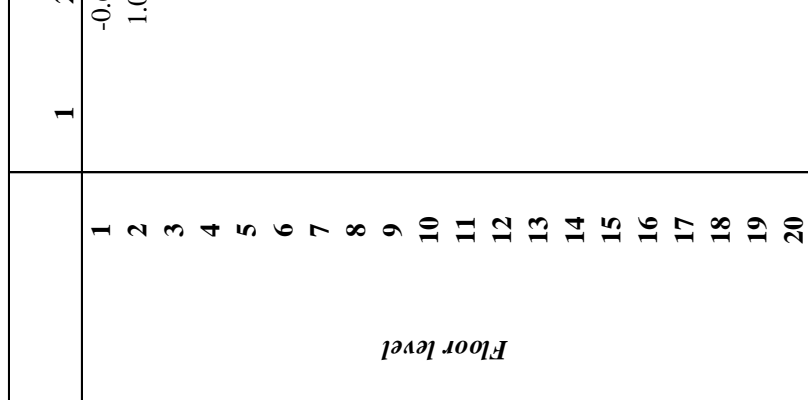



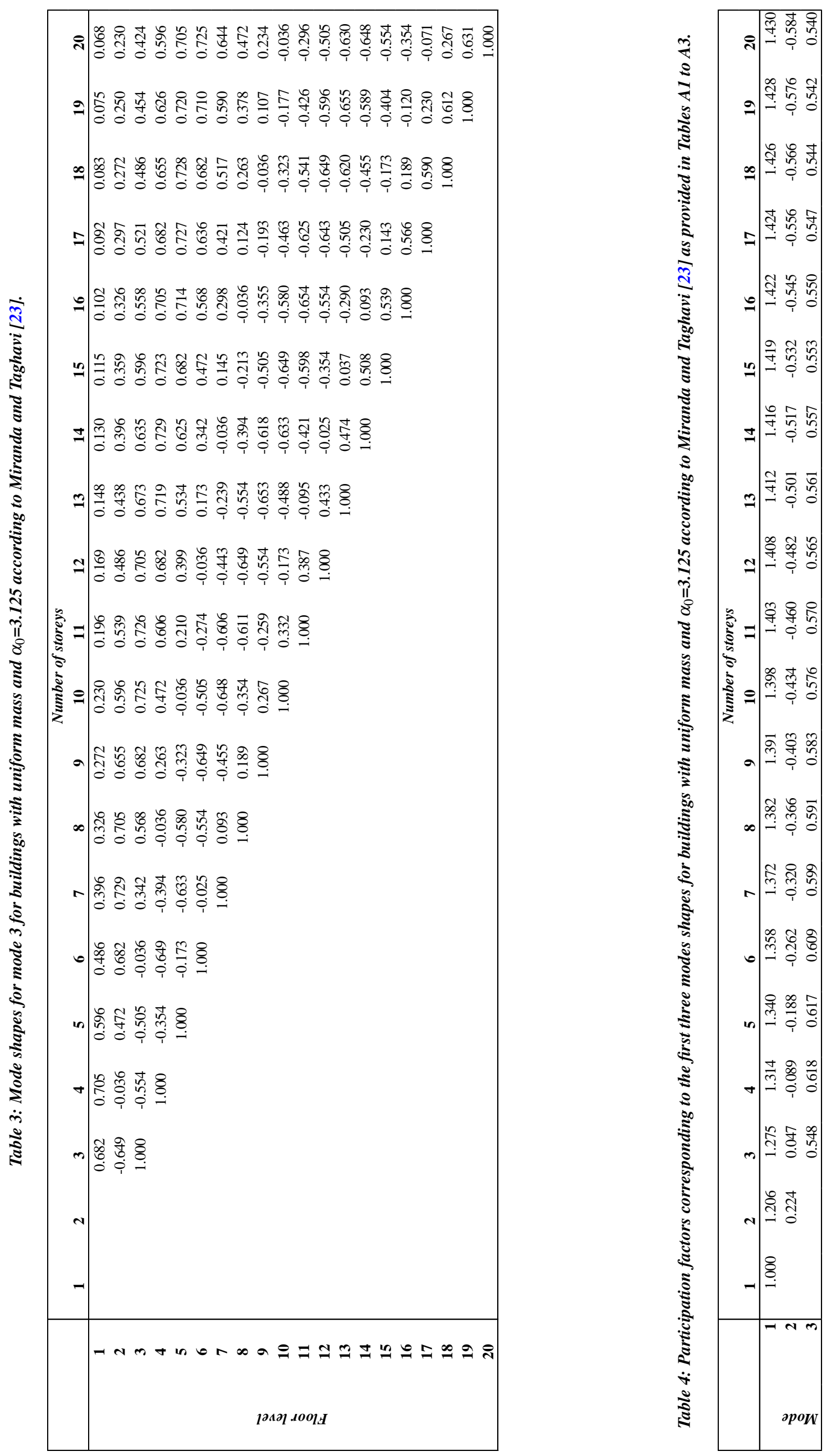